\title{
Impactos bibliométricos de la investigación científica en URACCAN, 2013-2017
}

\author{
Bibliometrics Impact of Scientific Research at URACCAN, 2013-2017
}

\author{
Juan Francisco Perera Lumbí ${ }^{1}$ \\ Wilson Antonio calero Borge ${ }^{2}$ \\ Neidy Gutiérrez Soza ${ }^{3}$ \\ Rosa Aura Palacios Rizo ${ }^{4}$ \\ Carolina Blanco Marchena ${ }^{5}$
}

\section{Resumen}

El presente artículo comparte los impactos bibliométricos de la investigación científica de la Universidad de las Regiones Autónomas de la Costa Caribe Nicaragüense (URACCAN), se ha enfatizado en la producción y publicación, tanto impresa como digital, durante 2013-2017. La investigación se desarrolló bajo el enfoque cuantitativo de corte transversal.

Entre los principales resultados sobresalen: i) La producción científica de URACCAN, del 2013-2017 fue de 787 investigaciones, de las que un 78.5\% corresponde a investigaciones monográficas, $10.8 \%$ a tesis y $10.7 \%$ a investigaciones libres de institutos, centros de investigación, docentes investigadores y personal de áreas técnicas; ii) Del 2013 al 2017 la URACCAN publicó un total de 20 números de sus revistas científicas, con 169 artículos, 89 en la revista Ciencia e Interculturalidad y 80 en la Revista Universitaria del Caribe; iii) La publicación científica de la Universidad en formato digital ha sido muy exitosa, desde junio del 2011 a enero del 2018, en tres portales, se hicieron un total de 574,649 descargas de artículos en formato pdf, de estos, 333,488 descargas se hicieron en el Portal de revistas de URACCAN, 205,853 en Lamjol y 35,308 en el Portal de revistas de Nicaragua; iv) En el período de agosto del 2015 a noviembre del 2018, la revista Ciencia e Interculturalidad obtiene el primer lugar en descargas de artículos de las revistas de universidades públicas, y el segundo lugar general de 49 revistas de Nicaragua, Honduras y El Salvador, alojadas en Lamjol.

\footnotetext{
1 Master en Ciencias Forestales. Director de Investigación y Posgrado de la Universidad de las Regiones Autónomas de la Costa Caribe Nicaragüense (URACCAN). Email: frankperera@yahoo.com - Orcid: https://orcid.org/oooo-0002-3837-3705

2 Máster en Agroforestería Tropical. Coordinador de Investigación y Postgrado de la Universidad de las Regiones Autónomas de la Costa Caribe Nicaragüense-Recinto Nueva Guinea. Correo: wilsoncalero@yahoo.com Orcid: https://orcid.org/oooo-0003-4243-0490

3 Master en Antropología Social con mención en Desarrollo Humano. Coordinador de Investigación y Postgrado de la Universidad de las Regiones Autónomas de la Costa Caribe Nicaragüense-Recinto Bluefields. Correo: neidygs@yahoo.com

4 Máster en Docencia Universitaria. Coordinadora de Investigación y Posgrado de la Universidad de las Regiones Autónomas de la Costa Caribe Nicaragüense, recinto Bilwi. Email: rosapalacios62@yahoo.es

5 Máster en Docencia Universitaria. Coordinadora de Investigación y Postgrado de la Universidad de las Regiones Autónomas de la Costa Caribe Nicaragüense-Recinto Las Minas. Correo: creacionrecreacion.lasminas@uraccan.edu.ni - Orcid: https://orcid. org/oooo-0002-0637-6477
} 
Palabras clave: Revistas electrónicas; Ranking, artículos más leídos, Ciencia e Interculturalidad; Revista Universitaria del Caribe.

\section{Abstract}

The current article shares the Bibliometrics Impact of Scientific Research at The University of the Autonomous Regions of the Nicaraguan Caribbean Coast (URACCAN), it is focused in the printed and digital research production and publishing between 2013 - 2017. The research was developed under the quantitative approach with a cross-sectional scope.

Among the main results stand out: i) URACCAN scientific production from 20132017 were 787 investigations, of which $78.5 \%$ corresponds to monographic research, $10.8 \%$ to thesis and $10.7 \%$ to free research from the institutes, research centers, teacher researchers and personnel from technical areas; ii) From 2013 to 2017, URACCAN published a total of 20 issues of its scientific journals, with 169 articles, 89 in the Science and Intercultural Magazine and 80 in the University Journal of the Caribbean; iii) The scientific publication of the University in digital format has been very successful, from June 2011 to January 2018, in three portals, a total of 574,649 downloads of articles were made in pdf format, from these ones, 333,488 downloads were made in the Portal of URACCAN Magazines, 205,853 in the Directory of Academic Journal Lamjol and 35,308 in the Portal of Nicaragua Magazines; iv) From August 2015 to November 2018, the Science and Interculturality Magazine obtains the first place in downloads of articles from the public universities journals, and the second place overall of 49 journals from Nicaragua, Honduras and El Salvador, hosted in Lamjol.

Keywords: Digital Magazines, Ranking, Most read articles, Science and Interculturality, University Journal of the Caribbean.

\section{Introducción}

La Universidad de las Regiones Autónomas de la Costa Caribe Nicaragüense (URACCAN), ha desarrollado grandes esfuerzos para fortalecer los procesos y capacidades investigativas en todos los eslabones en que se articula la investigación científica, con el propósito de producir investigaciones de calidad y pertinentes, aun así no existen estudios que indiquen o refieran los impactos de la producción científica, por ello se hace necesario la evaluación de indicadores de Investigación con el fin expreso de obtener información sobre el comportamiento de la investigación. Se considera que obtener esta información dará pautas para planificar mejor los procesos investigativos, servirá de insumo para las autoridades universitarias, y será de gran utilidad para los investigadores y docentes de la universidad. 
La URACCAN (2018), incorporó en su Plan estratégico 2015-2019, la realización de "una evaluación del impacto de las investigaciones desarrolladas"; por otra parte, el Consejo Nacional de Universidades (2012), contempla en su Plan Estratégico 2012-2021, la realización de la "Evaluación del impacto de los resultados de las investigaciones" en las universidades miembros del CNU. Para el desarrollo de esta investigación, en el 2017 se elaboró y aprobó por el Consejo Universitario de URACCAN, los "Indicadores para medir el impacto de la creación y recreación de conocimientos, saberes y prácticas en URACCAN" (URACCAN, 2017).

La evaluación del impacto de la ciencia y la tecnología constituye una necesidad estratégica como vía para constatar el desarrollo de un país, de su política científica y de su gestión en función de la sociedad y de los seres humanos que conviven en ella. Sobre su pertinencia e importancia se pronuncian varios autores que investigan y publican sobre este aspecto, tales como Cortés (2007).

En el marco de lo anterior, la URACCAN desarrolló en el 2018 la presente investigación. Este artículo comparte los resultados de la producción científica y los impactos bibliométricos de la publicación de los resultados para el período 2013-2017.

\section{Revisión de literatura}

El primer estudio de impactos bibliométricos realizado por la universidad se realizó y publicó en el año 2013, y se denominó "Ranking de artículos más leídos de la URACCAN publicados en sus revistas electrónicas con acceso abierto", y entre sus principales resultados reflejó el éxito de las revistas digitales de la Universidad, ubicado a la Revista Ciencia e Interculturalidad como una de las tres revistas más consultadas, en el período de agosto de 2010 a junio de 2012, en Latin American Jornal Online (Perera Lumbí, 2013).

Zeledón y Miranda (2018) realizaron el estudio: Utilidad de las investigaciones monográficas de los graduados y graduadas de URACCAN, Nueva Guinea, durante 2003-2009, en el mismo los autores encuentran que las monografías han tenido utilidad, como objeto de consultas bibliográficas, generación de proyectos, soluciones de problemáticas relacionadas con el quehacer universitario y regional, mejoramiento de los procesos de enseñanza aprendizaje, generación de datos y diagnósticos de problemáticas, construcción de nuestra historia municipal, aportes a la preservación del medio ambiente, alternativas de producción y mejoramiento de los sistemas agropecuario y forestal.

En otro estudio realizado por Bush y Williamson (2013) titulado: Diagnóstico situacional de la gestión investigativa en la Universidad de las Regiones Autónomas de la Costa Caribe Nicaragüense, Recinto Bilwi, 2010-2012, mencionan que, en términos de los procesos evaluativos de las investigaciones, URACCAN ha trabajado las primeras 
aproximaciones en referencia a los criterios de calidad y pertinencia de las investigaciones; sin embargo, requiere de mayor profundización y su validación consiguiente.

\section{La evaluación del impacto de las investigaciones}

Los indicadores de impacto son factores o variables que proveen un medio simple y confiable para medir impactos o cambios generados a partir de la investigación; buscan identificar los resultados obtenidos por los proyectos de investigación en sus diferentes modalidades y se basan en aspectos cuantitativos y cualitativos (Nave-Herrera, 2017).

La investigación aporta resultados científicos a través de diferentes vías, los cuales son evaluados a través de la cienciometría, que es la disciplina que aplica técnicas bibliométricas a dichos resultados mediante indicadores cienciométricos para evaluar su impacto científico y el desarrollo de políticas científicas (Spinak, 1998), así como para identificar las leyes y regularidades de la actividad científica en su sentido global y penetrar en la gestión de la ciencia (Cortés, 2007).

El impacto científico es el efecto producido por la novedad y el aporte teóricopráctico de los nuevos conocimientos como resultado del proceso investigativo, los cuales son aceptados y divulgados a través de diferentes publicaciones oficiales, reconocidos y citados por la comunidad de investigadores. No debe ser concebido solamente como un resultado final, sino también como un proceso de crecimiento individual y social (Hernández et al., 2005).

\section{Metodología y materiales}

El estudio se realizó en la URACCAN, durante el 2018. Se desarrolló desde el enfoque cuantitativo de corte transversal (2013-2017), aplicándose los indicadores para medir impactos bibliométricos de la investigación. Se consideró como población el total de las investigaciones concluidas y publicadas (investigaciones libres, tesis y monografías), según el corte establecido en el estudio, y la unidad de análisis las investigaciones concluidas y publicadas.

Para identificar los impactos bibliométricos de la producción y publicación científica de URACCAN, se analizó el comportamiento de las revistas "Ciencia e Interculturalidad" y la "Revista Universitaria del Caribe" en los siguientes portales: Portal de Latin American Journals Online (LAMJOL), Portal de Revistas de Nicaragua y Portal de Revistas de URACCAN. Para definir el ranking de los artículos más consultados en cada portal, se utilizó como indicador principal el número de descargas de artículos completos. 


\section{Resultados y discusión}

\section{La producción científica de URACCAN, período 2013 a 2017}

La producción científica de la URACCAN, descansa fundamentalmente en las investigaciones estudiantiles de grado y posgrado con fines de titulación. Para el período 2013 a 2017, en la Universidad se produjo un total de 787 investigaciones, de las que un $78.5 \%$ corresponde a investigaciones monográficas, $10.8 \%$ a tesis y $10.7 \%$ a investigaciones libres que hace el personal de institutos, centros de investigación, docentes investigadores y personal de áreas técnicas (cuadro 1).

Una de las grandes preocupaciones en los últimos años, dentro de la universidad, ha sido el riesgo de disminución drástica en el número de investigación que concluyen cada año por el efecto de la implementación de los exámenes de grado como forma de culminación; no obstante, en la revisión de las estadísticas del período en estudio, se encontró que la tendencia es a mantenerse estable, oscilando entre las 153 y 160 investigaciones concluidas por año, con un promedio de 157.4.

Referente al comportamiento por recinto, los datos demuestran que la producción científica se distribuye en un $28.46 \%$ en el recinto Nueva Guinea, $26.30 \%$ en el recinto Las Minas, $23.76 \%$ en el recinto Bilwi y un 21.46\% en el recinto Bluefields.

Cuadro No. 1: Producción científica de URACCAN, período 2013 a 2017

\begin{tabular}{|c|l|l|l|l|l|l|}
\hline \multirow{2}{*}{ Año } & \multirow{2}{*}{ Recinto } & \multicolumn{3}{c|}{ Número por tipo de investigación } & \multirow{2}{*}{ Total } & \% \\
\cline { 3 - 7 } & & Monografía & Tesis de Posgrado & Libres & & \\
\hline 2013 & Total & 91 & 25 & 42 & 158 & 100 \\
\hline & Recinto Las Minas & 14 & 0 & 2 & 16 & 10.13 \\
\hline & Recinto Bilwi & 7 & 24 & 16 & 71 & 44.94 \\
\hline & Recinto Nueva Guinea & 41 & 1 & 0 & 42 & 26.58 \\
\hline & Recinto Bluefields & 29 & 0 & 24 & 53 & 33.54 \\
\hline 2014 & Total & 132 & 2 & 19 & 153 & 100 \\
\hline & Recinto Las Minas & 12 & 0 & 3 & 15 & 9.80 \\
\hline & Recinto Bilwi & 23 & 1 & 13 & 37 & 24.18 \\
\hline & Recinto Nueva Guinea & 53 & 0 & 2 & 55 & 35.95 \\
\hline & Recinto Bluefields & 44 & 1 & 1 & 46 & 30.07 \\
\hline 2015 & Total & 106 & 43 & 11 & 160 & 100 \\
\hline & Recinto Las Minas & 38 & 27 & 3 & 68 & 42.5 \\
\hline & Recinto Bilwi & 40 & 1 & 3 & 44 & 27.5 \\
\hline & Recinto Nueva Guinea & 20 & 5 & 1 & 26 & 16.25 \\
\hline
\end{tabular}


EDUCACIÓN

\begin{tabular}{|c|c|c|c|c|c|c|}
\hline \multirow{2}{*}{ Año } & \multirow{2}{*}{ Recinto } & \multicolumn{3}{|c|}{ Número por tipo de investigación } & \multirow{2}{*}{ Total } & \multirow{2}{*}{$\%$} \\
\hline & & Monografía & Tesis de Posgrado & Libres & & \\
\hline & Recinto Bluefields & 8 & 10 & 4 & 22 & 13.75 \\
\hline \multirow[t]{5}{*}{2016} & Total & 144 & 11 & 4 & 159 & 100 \\
\hline & Recinto Las Minas & 60 & 1 & 1 & 62 & 38.99 \\
\hline & Recinto Bilwi & 29 & 0 & 0 & 29 & 18.24 \\
\hline & Recinto Nueva Guinea & 31 & 10 & 0 & 41 & 25.79 \\
\hline & Recinto Bluefields & 24 & 0 & 3 & 27 & 16.98 \\
\hline \multirow[t]{7}{*}{2017} & Total & 145 & 4 & 8 & 157 & 100 \\
\hline & Recinto Las Minas & 46 & 0 & 0 & 46 & 29.30 \\
\hline & Recinto Bilwi & 29 & 1 & 0 & 30 & 19.11 \\
\hline & Recinto Nueva Guinea & 52 & 3 & 5 & 60 & 38.22 \\
\hline & Recinto Bluefields & 18 & 0 & 3 & 21 & 13.38 \\
\hline & Total & 618 & 85 & 84 & 787 & \\
\hline & $\%$ & 78.53 & 10.80 & 10.67 & $100 \%$ & \\
\hline \multirow[t]{5}{*}{ 2013-2017 } & Total general & 618 & 85 & 84 & 787 & 100 \\
\hline & Recinto Las Minas & 170 & 28 & 9 & 207 & 26.30 \\
\hline & Recinto Bilwi & 128 & 27 & 32 & 187 & 23.76 \\
\hline & Recinto Nueva Guinea & 197 & 19 & 8 & 224 & 28.46 \\
\hline & Recinto Bluefields & 123 & 11 & 35 & 169 & 21.47 \\
\hline
\end{tabular}

Nota: No incluye investigaciones de cursos.

\section{El camino de la publicación científica en URACCAN}

De acuerdo a Perera Lumbí (2013), los primeros esfuerzos de URACCAN para publicar resultados de las investigaciones en formato de artículos inició en 1999 con la creación de la Revista Universitaria Caribe; posteriormente, en el 2008 se crea la Revista Ciencia e Interculturalidad, ambas en formato impreso. A inicios del 2011 se crea y publica la versión digital de ambas revistas.

La incursión de la universidad en la publicación científica en formato digital, está estrechamente vinculada al apoyo brindado por el Programa para el Fortalecimiento de la Información para la Investigación (PERI), el cual fue creado y desarrollado por el Consejo Nacional de Universidades (CNU), y surge en el 2006 como una iniciativa para acompañar y fortalecer el acceso a la información para la investigación dentro del sistema de investigación universitaria nicaragüense. Entre otras cosas, PERI aseguró el proceso de sensibilización y capacitación de directores en los procesos de Gestión de Revistas Electrónicas con Open Journal System (OJS). 
En marzo del 2011 se publica el Portal de Revistas de URACCAN, el que aglutina tres revistas: Ciencia e Interculturalidad, Revista Universitaria del Caribe y Uraccan al Día. En abril del 2011, la revista Ciencia e Interculturalidad ingresa al portal de Latin America Journals Online, sitio web que apoya la publicación en línea.

En marzo del 2011, la versión impresa de Ciencia e Interculturalidad ingresa al catálogo del portal del Sistema Regional de Información en Línea para Revistas Científicas de América Latina, el Caribe y Portugal (Latindex), y en mayo del 2012 ingresa la versión digital. Latindex, que es un sistema de información sobre las revistas de investigación científica, técnico-profesionales y de divulgación científica y cultural que surgió en 1995 en la Universidad Nacional Autónoma de México (UNAM) y se convirtió en una red de cooperación regional a partir de 1997.

En el 2012 la revista Ciencia e interculturalidad ingresa al Portal de Revistas Nacionales de Nicaragua, este portal aglutina solamente las revistas científicas que cumplen los criterios de calidad estipulados por Latindex para ingresar al catálogo.

\section{Investigaciones publicadas}

Durante 2013-2017, la URACCAN publicó un total de 20 números de sus revistas científicas, Ciencia e Interculturalidad y la Revista Universitaria del Caribe, ambas revistas tienen una frecuencia semestral. En total se publicaron 169 artículos, 89 en Ciencia e Interculturalidad y 80 en la Revista Universitaria del Caribe (Cuadro 2). Del total de artículos publicados, 30 corresponden a autores externos. Por otra parte, en revistas internacionales se tienen registrados 11 artículos científicos publicados.

La publicación por recinto universitario y la realizada por el personal de la Oficina de Enlace se comportó de la siguiente manera: 39 artículos del Recinto Nueva Guinea, 16 del Recinto Las Minas, 17 del Recinto Bilwi, 25 del Recinto Bluefields y 42 de la Oficina de Enlace. En materia de otras publicaciones se tienen registrados 21 libros (Cuadros 3) y 11 documento referidos a políticas, normativas y reglamentos institucionales (Cuadros 4).

Cuadro No. 2: Resumen de artículos publicados en las revistas de URACCAN, del 2013 al 2017

\begin{tabular}{|l|l|l|l|l|l|}
\hline$\#$ & \multicolumn{1}{|c|}{ Revista } & \multicolumn{1}{|c|}{ Año } & \multicolumn{1}{|c|}{ Volumen } & No. artículos & $\begin{array}{c}\text { No. artículos } \\
\text { externos }\end{array}$ \\
\hline 1 & Ciencia e Interculturalidad & 2013 & Volumen 12 No. 1 & 9 & 1 \\
\hline 2 & Ciencia e Interculturalidad & 2013 & Volumen 13 No. 2 & 10 & 0 \\
\hline 3 & Ciencia e Interculturalidad & 2014 & Volumen 14 No.1 & 9 & 3 \\
\hline 4 & Ciencia e Interculturalidad & 2014 & Volumen 15 No. 2 & 10 & 3 \\
\hline 5 & Ciencia e Interculturalidad & 2015 & Volumen 16 No. 1 & 8 & 1 \\
\hline
\end{tabular}




\section{EDUCACIÓN}

\begin{tabular}{|c|c|c|c|c|c|}
\hline$\#$ & Revista & Año & Volumen & No. artículos & $\begin{array}{c}\text { No. artículos } \\
\text { externos }\end{array}$ \\
\hline 6 & Ciencia e Interculturalidad & 2015 & Volumen 17 No. 2 & 8 & 1 \\
\hline 7 & Ciencia e Interculturalidad & 2016 & Volumen 18 No. 1 & 8 & 2 \\
\hline 8 & Ciencia e Interculturalidad & 2016 & Volumen 19 No. 2 & 9 & 4 \\
\hline 9 & Ciencia e Interculturalidad & 2017 & Volumen 20 No. 1 & 9 & 2 \\
\hline \multirow[t]{2}{*}{10} & Ciencia e Interculturalidad & 2017 & Volumen 21 No. 2 & 9 & 2 \\
\hline & Sub total & & & 89 & 19 \\
\hline 11 & $\begin{array}{l}\text { Revista Universitaria del } \\
\text { Caribe }\end{array}$ & 2013 & Volumen 10 No. 1 & 9 & 0 \\
\hline 12 & $\begin{array}{l}\text { Revista Universitaria del } \\
\text { Caribe }\end{array}$ & 2013 & Volumen 11 No. 2 & 11 & 0 \\
\hline 13 & $\begin{array}{l}\text { Revista Universitaria del } \\
\text { Caribe }\end{array}$ & 2014 & Volumen 12 No. 1 & 6 & 1 \\
\hline 14 & $\begin{array}{l}\text { Revista Universitaria del } \\
\text { Caribe }\end{array}$ & 2014 & Volumen 13 No. 2 & 8 & 0 \\
\hline 15 & $\begin{array}{l}\text { Revista Universitaria del } \\
\text { Caribe }\end{array}$ & 2015 & Volumen 14 No. 1 & 5 & 0 \\
\hline 16 & $\begin{array}{l}\text { Revista Universitaria del } \\
\text { Caribe }\end{array}$ & 2015 & Volumen 15 No. 2 & 6 & 2 \\
\hline 17 & $\begin{array}{l}\text { Revista Universitaria del } \\
\text { Caribe }\end{array}$ & 2016 & Volumen 16 No. 1 & 6 & 2 \\
\hline 18 & $\begin{array}{l}\text { Revista Universitaria del } \\
\text { Caribe }\end{array}$ & 2016 & Volumen 17 No. 2 & 8 & 3 \\
\hline 19 & $\begin{array}{l}\text { Revista Universitaria del } \\
\text { Caribe }\end{array}$ & 2017 & Volumen 18 No. 1 & 10 & 1 \\
\hline 20 & $\begin{array}{l}\text { Revista Universitaria del } \\
\text { Caribe }\end{array}$ & 2017 & Volumen 19 No. 2 & 11 & 2 \\
\hline & Sub total & & & 80 & 11 \\
\hline & Gran total & & & 169 & 30 \\
\hline
\end{tabular}

Cuadro No. 3: Libros publicados del 2013 al 2017

\begin{tabular}{|l|l|}
\hline No. & \multicolumn{1}{|c|}{ Publicaciones } \\
\hline & \multicolumn{1}{|c|}{ Publicaciones 2014 } \\
\hline 1 & $\begin{array}{l}\text { Estudios Tipos de Tenencia de Propiedad en la Costa Caribe } \\
\text { "Informe Final". }\end{array}$ \\
\hline 2 & $\begin{array}{l}\text { Compendio Investigaciones de las Maestrías en Educación } \\
\text { Intercultural Bilingüe. }\end{array}$ \\
\hline
\end{tabular}




\begin{tabular}{|l|l|}
\hline No. & \multicolumn{1}{|c|}{ Publicaciones } \\
\hline 3 & Informe Final Línea de Base - Proyecto Salud para Todos. \\
\hline 4 & Recursos Humanos - Proyecto Salud para Todos. \\
\hline 5 & Documento Base - Proyecto Salud para Todos. \\
\hline 6 & Resumen de la Sistematización - Proyecto Salud para Todos. \\
\hline 7 & $\begin{array}{l}\text { Transparencia Intercultural, Interfaz entre las Instituciones } \\
\text { Modernas y Tradicionales en el Saneamiento y Agua Potable. }\end{array}$ \\
\hline 8 & El Paradigma Educativo de Abya Yala. \\
\hline 9 & La Educación y Nosotras. Versión Español. \\
\hline 10 & La Educación y Nosotras. Versión Creole. \\
\hline 11 & Proyecto de AEl URACCAN. \\
\hline 12 & Informe Proyecto de AEI URACCAN. \\
\hline 13 & Perfil Institucional URACCAN. \\
\hline 14 & $\begin{array}{l}\text { Modelo de Atención Intercultural del Régimen especial Alto } \\
\text { Wangki-Bocay (MASIRE-AWB) 2014. }\end{array}$ \\
\hline & \\
\hline 15 & Proyecto Educativo Institucional URACCAN. \\
\hline 16 & Guía Regional de Atención a la Malaria. \\
\hline 17 & Resumen Ejecutivo del Plan Estratégico URACCAN 2015 - 2019. \\
\hline 18 & Plan Estratégico URACCAN 2015 - 2019. \\
\hline 19 & Plan de mejoras de URACCAN 2015 -2018. \\
\hline 20 & Cultivo y crianza de sabidurías y conocimientos ((CCRISAC). \\
\hline 21 & Espiritualidad y filosofía indígena. Avelino Cox Molina. \\
\hline
\end{tabular}

Cuadro No. 4: Políticas, normativas y reglamentos publicados del 2013 al 2017

\begin{tabular}{|l|l|l|}
\hline No. & \multicolumn{1}{|c|}{ Publicaciones } & \multicolumn{1}{|c|}{$\begin{array}{c}\text { Fecha de } \\
\text { Publicación }\end{array}$} \\
\hline 1 & Compendio Políticas, Reglamentos y Normativas de URACCAN 2005-2009. & 2014 \\
\hline 2 & $\begin{array}{l}\text { Política de Gestión Intercultural de Cooperación Externa de URACCAN con } \\
\text { Perspectiva de Género. }\end{array}$ & 2014 \\
\hline 3 & Compendio de Políticas, Reglamentos y Normativas de URACCAN 2008-2012. & 2015 \\
\hline 4 & Compendio de Acuerdos CUU 2012-2014. & 2015 \\
\hline 5 & Normativa de selección y funciones de tutores y jurados. & 2016 \\
\hline 6 & Reglamento Estudiantil. & 2017 \\
\hline 7 & Compilación de acuerdos CUU 2015-2016. & 2017 \\
\hline
\end{tabular}




\begin{tabular}{|l|l|l|}
\hline No. & \multicolumn{1}{|c|}{ Publicaciones } & \multicolumn{1}{|c|}{$\begin{array}{c}\text { Fecha de } \\
\text { Publicación }\end{array}$} \\
\hline 8 & Reglamento Interno de URACCAN. & 2017 \\
\hline 9 & $\begin{array}{l}\text { Política y Agenda Institucional de creación y recreación de conocimientos, } \\
\text { saberes y prácticas con perspectiva intercultural de género. }\end{array}$ & 2017 \\
\hline 10 & Normativa de propiedad intelectual. & 2017 \\
\hline 11 & Indicadores para medir el impacto de las investigaciones. & 2017 \\
\hline
\end{tabular}
Impacto de la publicación científica de URACCAN

\section{El Portal de Revistas de URACCAN}

El Portal de Revistas de URACCAN (figura 1) ha sido un éxito completo en materia de difusión de la publicación científica de la Universidad y sus investigadores colaboradores. El monitoreo que comprende de junio del 2011 a enero del 2018, refleja 233,929 revisiones de resúmenes de artículos y 333,488 descargas de artículos completos en formato pdf, lo anterior implica un promedio anual de 51,305 descargas de artículos completos y 35,989 de revisión de resúmenes. Estos datos corresponden a las revistas científicas Ciencia e Interculturalidad y la Revista Universitaria del Caribe (cuadro 5).

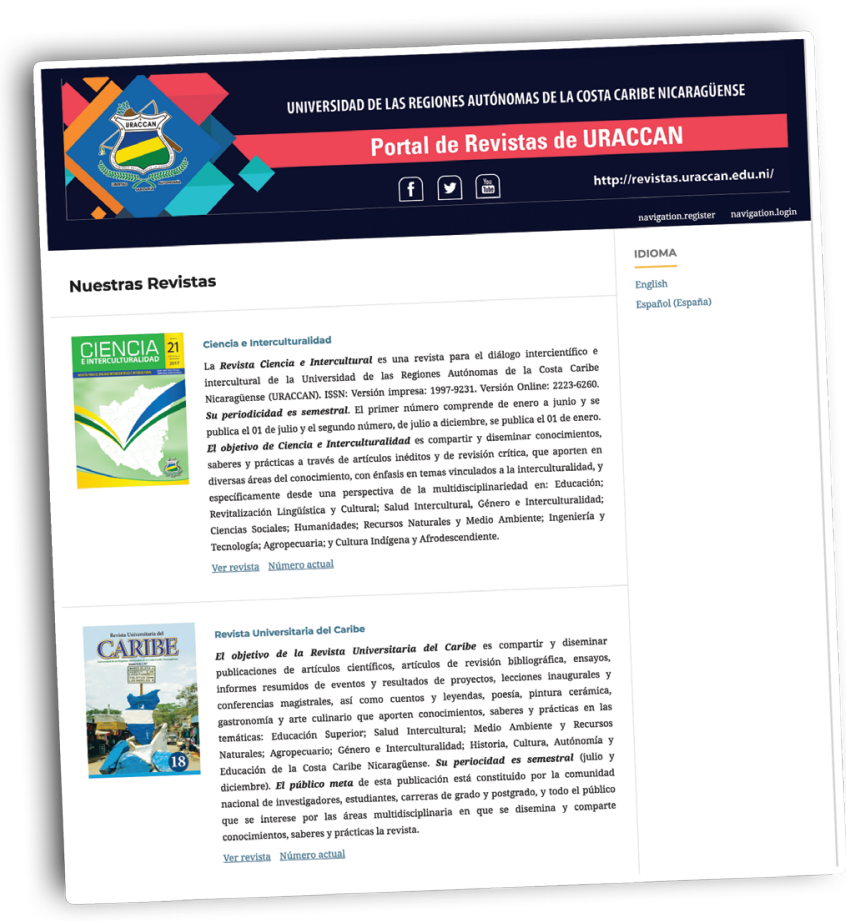

Figura No. 1. Portal de revistas de URACCAN, disponible en: http://revistas.uraccan.edu.ni/index.php/index. 
Cuadro No. 5: Resumen de visitas al Portal de Revistas de URACCAN, junio 2011 a enero del 2018

\begin{tabular}{|l|l|l|l|l|}
\hline \multirow{2}{*}{ Revista } & \multicolumn{4}{c|}{ Número y tipo de consultas } \\
\cline { 2 - 5 } & Leer resumen & $\%$ & $\begin{array}{c}\text { Descargar } \\
\text { pdf }\end{array}$ & $\%$ \\
\hline Ciencia e Interculturalidad & 118,345 & 50.6 & 171,601 & 51.5 \\
\hline Revista Universitaria del Caribe & 115,584 & 49.4 & 161,887 & 48.4 \\
\hline Total & 233,929 & 100 & 333,488 & 100 \\
\hline
\end{tabular}

Si analizamos el comportamiento para cada una de las revistas en el Portal de Revistas de URACCAN, Ciencia e Interculturalidad tiene un promedio anual de 26,400 descargas de artículos completos y 18,206 para revisar resúmenes; por su parte, la Revista Universitaria del Caribe tiene un promedio anual de 24,905 descargas de artículos completos y 17,782 para revisar resúmenes.

\section{Ranking de los artículos más consultados de la revista Ciencia e Interculturalidad en el Portal de Revistas de URACCAN}

En el ranking de los artículos más consultados de la revista Ciencia e Interculturalidad en el Portal de Revistas de URACCAN, se evidencia que predominan en los primeros lugares investigaciones vinculadas a la educación. Evidentemente, los artículos contenidos en números de revistas más recientes tienen desventaja para aparecer entre los más consultados, por el tiempo de permanencia en el portal (cuadro 6).

\section{Ranking de los artículos más consultados de la Revista Universitaria del Caribe en el Portal de Revistas de URACCAN}

En el ranking de los artículos más consultados de la Revista Universitaria del Caribe en el Portal de Revistas de URACCAN, se evidencia que predominan en los primeros lugares, investigaciones vinculadas a la cultura de la Costa Caribe (cuadro 7). 


\section{EDUCACIÓN}

Cuadro No. 6: Ranking de los artículos más consultados de la revista Ciencia e Interculturalidad en el Portal de Revistas de URACCAN, junio 2011 a enero del 2018.

\begin{tabular}{|c|c|c|c|c|}
\hline$\#$ & Título del artículo & Volumen & $\begin{array}{c}\text { Fecha de } \\
\text { publicación }\end{array}$ & $\begin{array}{l}\text { Descargas } \\
\text { PDF }\end{array}$ \\
\hline 1 & $\begin{array}{l}\text { Factores que influyen en el proceso de enseñanza-aprendizaje en el área español } \\
\text { como segunda lengua, en quinto y sexto grado en la modalidad de multigrado } \\
\text { en la escuela Bilingüe. Año } 2007 \text { a 2008. Rosita, RAAN. Autores: Isabel Lackwood } \\
\text { Bustillo, Zoraida Ruíz Rivera, Verónica Valdivia. }\end{array}$ & Vol 2, № 2 (2008) & $21 / 09 / 2012$ & 9973 \\
\hline 2 & $\begin{array}{l}\text { La desintegración familiar y el aprendizaje en niñas y niños de iv grado. Autores: } \\
\text { María Estela Vargas Tess, Nalia Rosales Cunningham, Argentina Garćáa Solórzano. }\end{array}$ & Vol 1, № 1 (2008) & 20/02/2012 & 8410 \\
\hline 3 & $\begin{array}{l}\text { Influencia de las fases lunares sobre el rendimiento del maíz (Zea mays, variedad } \\
\text { NB6). Autores: Larry Flores Martínez, Féliz Meléndez Mejía, Gladys Luna Bello, } \\
\text { Eliseo González Lazo. }\end{array}$ & Vol 10, № 1 (2012) & $17 / 10 / 2012$ & 5227 \\
\hline 4 & $\begin{array}{l}\text { Creencias y costumbres tradicionales del pueblo indígena misquitu de Kahkabila. } \\
\text { Autores: Lina Carlos Grádiz, Sonia Garth, Paula Ingram. }\end{array}$ & Vol 5, № 2 (2009) & 21/09/2012 & 5203 \\
\hline 5 & $\begin{array}{l}\text { Factores pedagógicos y socioeconómicos que inciden en el proceso en la mo- } \\
\text { dalidad de multigrado bilingüe: idiomas sumu-mayangna, en la comunidad de } \\
\text { Fruta de Pan, segundo semestre } 2007 \text { y primer semestre del 2008. Autores: Daysi } \\
\text { Lackwood Bustillo, Judith Edith Frank Pedro, Julia Argüello Mendieta. }\end{array}$ & Vol 2, № 2 (2008) & 21/09/2012 & 3128 \\
\hline 6 & $\begin{array}{l}\text { Etno-matemática en indígenas ulwas, comunidad de Karawala, Región } \\
\text { Autónoma Atlántico Sur, Nicaragua. Autores: Minerva Soza Valverde, Alba Luz } \\
\text { Dávila Espinoza. }\end{array}$ & Vol 11, No 2 (2012) & $14 / 02 / 2013$ & 2890 \\
\hline 7 & $\begin{array}{l}\text { Rendimiento de dos variedades mejoradas de frijol, sembrados al voleo y al es- } \\
\text { peque, en Moss Pam, Waspam, rio Coco. Autores: Sankara Keith Narvaez Ismale, } \\
\text { Hector R Marchena Williams, William J Watler Reyes, Enrique Cordón Suárez. }\end{array}$ & Vol 9, No 2 (2011) & $15 / 10 / 2012$ & 2321 \\
\hline 8 & $\begin{array}{l}\text { La ortografía acentual en la lengua miskitu: enriquecimiento de la Educación } \\
\text { Intercultural Bilingüe. Autores: Ruby Morales Quant, Marcos Padilla Brown, Yuri } \\
\text { Zapata Webb. }\end{array}$ & Vol 1, № 1 (2008) & 20/02/2012 & 2052 \\
\hline 9 & $\begin{array}{l}\text { Creencias y costumbres de la población kriol en Corn Island. Autores: Débora } \\
\text { Forbes Morales, Beverly Hendricks Gipson, Nubia Ordoñez. }\end{array}$ & Vol 5, № 2 (2009) & 21/09/2012 & 2016 \\
\hline 10 & $\begin{array}{l}\text { Estado de la biodiversidad terrestre de la Región Autónoma Atlántico Sur (RAAS), } \\
\text { Nicaragua. Autores: Christopher A Jordan, Kirkman Roe Hulse. }\end{array}$ & Vol 7, № 2 (2010) & 21/09/2012 & 1972 \\
\hline 11 & $\begin{array}{l}\text { Factores que inciden en el proceso de enseñanza - aprendizaje del español como } \\
\text { segunda lengua (L2), segundo grado, escuela Santo Tomás de Umbra, segundo } \\
\text { semestre del año 2007. Autores: Leandro Pekitle Pedro, Hernacio Pedro Maibeth, } \\
\text { Eloy Frank Gómez. }\end{array}$ & Vol 2, No 2 (2008) & 21/09/2012 & 1939 \\
\hline 12 & $\begin{array}{l}\text { Diagnóstico biofísico y socioeconómico de la cuenca Bilwi Tingni, Puerto Cabezas, } \\
\text { RAAN. Autores: Ulises Cordón Suárez, Wilfredo Johnson, Enrique Cordón Suárez. }\end{array}$ & Vol 2, No 2 (2008) & 21/09/2012 & 1839 \\
\hline 13 & $\begin{array}{l}\text { Enseñanza de la geometría en segundo año de educación secundaria bajo el } \\
\text { enfoque de competencias. Autores: Silguian Yamileth Gutiérrez M, Eugenio } \\
\text { Casimiro López Mairena. }\end{array}$ & Vol 6, № 1 (2010) & 21/09/2012 & 1794 \\
\hline
\end{tabular}




\begin{tabular}{|c|c|c|c|c|}
\hline$\#$ & Título del artículo & Volumen & $\begin{array}{l}\text { Fecha de } \\
\text { publicación }\end{array}$ & $\begin{array}{c}\text { Descargas } \\
\text { PDF }\end{array}$ \\
\hline 14 & $\begin{array}{l}\text { Interacciones educativas interculturales en las aulas de la URACCAN, Recinto } \\
\text { Bilwi. Autores: Marbel Baltodano Baltodano. }\end{array}$ & Vol 7, No 2 (2010) & 21/09/2012 & 1656 \\
\hline 15 & $\begin{array}{l}\text { Propuesta metodológica basada en competencia para la enseñanza de gráficas y } \\
\text { análisis de funciones trigonométrica. Autores: Blanca Rosa Gómez Reyes, Moisés } \\
\text { Medina López, Eugenio Casimiro López Mairena. }\end{array}$ & Vol 7, No 2 (2010) & 21/09/2012 & 1555 \\
\hline 16 & $\begin{array}{l}\text { Economía indígena en la comunidad Sikilta, municipio de Siuna, RAAN. Autores: } \\
\text { Pío Alejandro Garćáa Izaguirre, Saida De los Ángeles Argüello Mendieta. }\end{array}$ & Vol 8, № 1 (2011) & $12 / 01 / 2012$ & 1548 \\
\hline 17 & $\begin{array}{l}10 \text { años de historia fundacional de la URACCAN Siuna-Las Minas. Autores: Fredy } \\
\text { Leonel Valiente Contreras, Víctor Manuel Del Cid Lucero. }\end{array}$ & Vol 10, № 1 (2012) & $17 / 10 / 2012$ & 1408 \\
\hline 18 & $\begin{array}{l}\text { La revitalización de la lengua y cultura garífuna a través de la educación. Autores: } \\
\text { Vernadine López, Arja Koskinen. }\end{array}$ & Vol 5, № 2 (2009) & 21/09/2012 & 1387 \\
\hline 19 & $\begin{array}{l}\text { Los procesos educativos en Waslala, RAAN. Autores: Fredy Leonel Valiente } \\
\text { Contreras. }\end{array}$ & Vol 5, № 2 (2009) & 21/09/2012 & 1366 \\
\hline 20 & $\begin{array}{l}\text { Las repúblicas bolivariana de Venezuela y Nicaragua, en el marco del acuerdo } \\
\text { energético. Autores: Dani José Villalobos Soto. }\end{array}$ & Vol 11, No 2 (2012) & $14 / 02 / 2013$ & 1340 \\
\hline
\end{tabular}

Cuadro No. 7: Ranking de los artículos más consultados de la Revista Universitaria del Caribe en el Portal de Revistas de URACCAN, junio 2011 a enero del 2018.

\begin{tabular}{|l|l|c|c|l|}
\hline$\#$ & \multicolumn{1}{|c|}{ Título del artículo } & \multicolumn{1}{|c|}{ Volumen } & \multicolumn{1}{|c|}{$\begin{array}{c}\text { Fecha de } \\
\text { publicación }\end{array}$} & $\begin{array}{c}\text { Descargas } \\
\text { PDF }\end{array}$ \\
\hline 1 & $\begin{array}{l}\text { Vida, obra y pensamiento de MARCUS } \\
\text { GARVEY. Autores: Alta Hooker Blandford. }\end{array}$ & Vol 11, No 2 (2013) & 16/01/2014 & 5133 \\
\hline 2 & $\begin{array}{l}\text { Significado del Palo de Mayo. Autores: } \\
\text { Antonia MsCoy. }\end{array}$ & Vol 8, No 2 (2002) & $26 / 01 / 2012$ & 4548 \\
\hline 3 & $\begin{array}{l}\text { Cuentos y leyendas. Autores: Luisa Emilia } \\
\text { Ruiz, Napoléon Rojas, Edier Rosales, Mística } \\
\text { Blucha. }\end{array}$ & Vol 12, No 1 (2014) & $17 / 02 / 2015$ & 4077 \\
\hline 4 & $\begin{array}{l}\text { Cantos tradicionales de los pueblos miski- } \\
\text { tos. Autores: Gregorio Smutko. }\end{array}$ & Vol 3, No 2 (2000) & $21 / 09 / 2012$ & 3351 \\
\hline 5 & $\begin{array}{l}\text { Evaluación de abono orgánico sobre los } \\
\text { rendimientos productivos del cultivo del } \\
\text { maíz (Zea mays). Autores: Henry Marín } \\
\text { Sánchez, Noel Castillo Rodríguez, Lauren } \\
\text { Meléndez. }\end{array}$ & Vol 7, No 1 (2002) & $31 / 01 / 2012$ & 3109 \\
\hline 6 & $\begin{array}{l}\text { Un municipio de origen campesino. } \\
\text { Autores: Oscar Danilo González. }\end{array}$ & Vol 9, No 1 (2003) & 26/01/2012 & 3090 \\
\hline 7 & $\begin{array}{l}\text { El Sistema Educativo Autonómico } \\
\text { Regional. Autores: Alta Hooker Blandford. }\end{array}$ & Vol 11, No 2 (2013) & 16/01/2014 & 2859 \\
\hline
\end{tabular}




\begin{tabular}{|c|c|c|c|c|}
\hline$\#$ & Título del artículo & Volumen & $\begin{array}{l}\text { Fecha de } \\
\text { publicación }\end{array}$ & $\begin{array}{l}\text { Descargas } \\
\text { PDF }\end{array}$ \\
\hline 8 & $\begin{array}{l}\text { Ansiedades del pueblo Rama. Autores: } \\
\text { Josefina Moreno, María Isabel Moreno, } \\
\text { Yolanda Valverde, Dinora Espinoza. }\end{array}$ & Vol 2, No 1 (2000) & 26/03/2012 & 2790 \\
\hline 9 & $\begin{array}{l}\text { Derechos de los pueblos indígenas y } \\
\text { afrodescendientes en América Latina y en } \\
\text { Nicaragua. Autores: Fredy Leonel Valiente } \\
\text { Contreras. }\end{array}$ & Vol 12, No 1 (2014) & $17 / 02 / 2015$ & 2594 \\
\hline 10 & $\begin{array}{l}\text { Los efectos de la luna en la producción } \\
\text { agropecuaria. Autores: Aura Danelia } \\
\text { Vásquez Cabrera, Jaritza Maquiel Narváez } \\
\text { Gago, Wilson Antonio Calero Borge. }\end{array}$ & Vol 13, No 2 (2014) & 10/07/2015 & 2368 \\
\hline 11 & $\begin{array}{l}\text { Historia de los primeros años de Siuna. } \\
\text { Autores: Juan Francisco Perera Lumbí," } \\
\text { Carlos Guillen Torrentes, Francois Cyprian. }\end{array}$ & Vol 11, No 2 (2013) & $16 / 01 / 2014$ & 1864 \\
\hline 12 & $\begin{array}{l}\text { Diagnóstico de la situación de los pastos } \\
\text { en la época seca en el municipio de Siuna. } \\
\text { Autores: Iván Jarquín, Luis Herrera, Yamil } \\
\text { Castillo, Eloy Soza, Oscar Montalbán. }\end{array}$ & Vol 5, No 2 (2001) & $08 / 02 / 2012$ & 1798 \\
\hline 13 & $\begin{array}{l}\text { Poesía e interculturalidad. Autores: } \\
\text { Fernando José Saavedra Areas. }\end{array}$ & Vol 12, No 1 (2014) & $17 / 02 / 2015$ & 1763 \\
\hline 14 & $\begin{array}{l}\text { Diagnóstico rural participativo en la co- } \\
\text { municación intercultural bilingüe para la } \\
\text { protección de los recursos naturales en las } \\
\text { comunidades indígenas de la laguna de } \\
\text { Pahra (Tuapi, Krukira, Pahra y Awastara). } \\
\text { Autores: Juan Francisco Perera Lumbí. }\end{array}$ & Vol 5, No 2 (2001) & 08/02/2012 & 1647 \\
\hline 15 & $\begin{array}{l}\text { The will and testament of Martha Downs. } \\
\text { Autores: Edmundo Gordon. }\end{array}$ & Vol 8, No 2 (2002) & 26/01/2012 & 1645 \\
\hline 16 & $\begin{array}{l}\text { Guía de semillas, vivero y plantaciones de } \\
\text { Pinus Caribae Morelet variedad honduren- } \\
\text { sis (Seneclauze). Autores: Juan Francisco } \\
\text { Perera Lumbí, Miguel Ángel Musálem. }\end{array}$ & Vol 5, No 2 (2001) & $08 / 02 / 2012$ & 1580 \\
\hline 17 & $\begin{array}{l}\text { Cultura de poder. Literatura indígena y } \\
\text { afrocaribeña en Nicaragua. Autores: Carlos } \\
\text { Alemán Ocampo. }\end{array}$ & Vol 2, No 1 (2000) & 26/03/2012 & 1500 \\
\hline 18 & $\begin{array}{l}\text { Primer Simposio Internacional de } \\
\text { Educación Bilingüe Intercultural } \\
\text { Mayangna. Autores: Eloy Frank, Melba } \\
\text { Mclean, Jane Freeland, Elena Benedicto, } \\
\text { Melvin James. }\end{array}$ & Vol 4, No 1 (2001) & 24/02/2012 & 1408 \\
\hline
\end{tabular}




\begin{tabular}{|c|l|c|c|c|}
\hline$\#$ & \multicolumn{1}{|c|}{ Título del artículo } & Volumen & $\begin{array}{c}\text { Fecha de } \\
\text { publicación }\end{array}$ & $\begin{array}{c}\text { Descargas } \\
\text { PDF }\end{array}$ \\
\hline 19 & $\begin{array}{l}\text { Potencial productivo y desarrollo sosteni- } \\
\text { ble. Autores: Wilson Calero Borge. }\end{array}$ & Vol 9, No 1 (2003) & $26 / 01 / 2012$ & 1406 \\
\hline 20 & $\begin{array}{l}\text { 2002 world Summit on sustainable de- } \\
\text { veloment regional roundtable for latin } \\
\text { america and Caribbean report. Autores: } \\
\text { Naciones Unidas. }\end{array}$ & Vol 5, No 2 (2001) & $08 / 02 / 2012$ & 1406 \\
\hline
\end{tabular}

\section{Las revistas de URACCAN en Latin American Jornal Online}

El primer boletín informativo de INASP (2012), reportó paro el período de agosto del 2010 a junio de 2012, la revista Ciencia e Interculturalidad se situó en tercer lugar en consultas de artículos, y dos de sus artículos integraron la lista de los 10 más consultados, estos son:

a. Gutiérrez M, S., \& López Mairena, E. (2010). Enseñanza de la geometría en segundo año de educación secundaria bajo el enfoque de competencias. Ciencia e Interculturalidad, 6(1), 110-119.

b. Sevilla Núñez, D., Puerta Chavarría, V., \& Dávila Molina, J. (2010). Influencia de los factores socioeconómicos en la deserción estudiantil de la carrera de ciencias sociales. Ciencia e Interculturalidad, 6(1), 72-84.

En el boletín informativo de Lamjol (INASP, 2014), reporta que, de julio de 2012 a junio de 2014, las revistas especializadas que más se descargaron fueron Ciencia e Interculturalidad (53,199 descargas), Wani (53,075), Revista de Derecho $(51,786)$ y Nexo.

Revista Científica (50,939), y dos de los 10 artículos más consultados corresponden a la revista Ciencia e Interculturalidad, estos son:

a. Lackwood Bustillo, I., Ruíz Rivera, Z., \& Valdivia, V. (2008). Factores que influyen en el proceso de Enseñanza aprendizaje en el área español como segunda lengua, en quinto y sexto grado en la modalidad de multigrado en la escuela Bilingüe: “Enmanuel”. Año 2007 - 2008, Rosita, RAAN. Ciencia e Interculturalidad, 2(2), 104-124.

b. Vargas Tess, M., Rosales Cunningham, N., \& García Solórzano, A. (2008). La desintegración familiar y el aprendizaje en niñas y niños de IV grado. Ciencia e Interculturalidad, 1(1), 45-61.

\section{Consultas históricas de artículos en Lamjol}

En el monitoreo global realizado al Portal de Latin American Jornal Online (Lamjol), para el período de marzo del 2011 a noviembre del 2018, la revista Ciencia e Interculturalidad contabiliza un total de 205,853 consultas de sus artículos, estas cifras no incluyen las 
consultas del período de noviembre 2013 a julio 2015, del que no se tienen registros. Referente a la Revista Universitaria del Caribe contabiliza un total de 5,634 consultas en el período comprendido de febrero 2017 a octubre del 2018 (cuadro 8).

Cuadro No. 8: Consultas de las revistas de URACCAN en Latin American Jornal online (Lamjol), del 2011 a noviembre del 2018

\begin{tabular}{|l|l|l|l|l|l|l|l|l|l|}
\hline \multicolumn{1}{|c|}{ Descripción } & $\mathbf{2 0 1 1}$ & $\mathbf{2 0 1 2}$ & $\begin{array}{c}\text { Enero a } \\
\text { oct 2013 }\end{array}$ & $\begin{array}{l}\text { Nov 2013 a } \\
\text { julio 2015 }\end{array}$ & $\begin{array}{l}\text { Agosto a } \\
\text { dic 2015 }\end{array}$ & $\mathbf{2 0 1 6}$ & $\mathbf{2 0 1 7}$ & $\begin{array}{c}\text { Enero a } \\
\text { nov } \mathbf{2 0 1 8}\end{array}$ & Total \\
\hline $\begin{array}{l}\text { Ciencia e } \\
\text { Interculturalidad }\end{array}$ & 10,335 & 19,365 & $\mathbf{2 4 , 0 5 7}$ & sd & 11,768 & 25,490 & $\mathbf{3 9 , 7 7 8}$ & $\mathbf{7 5 , 6 6 0}$ & $\mathbf{2 0 5 , 8 5 3}$ \\
\hline $\begin{array}{l}\text { Revista } \\
\text { Universitaria del } \\
\text { Caribe }\end{array}$ & 0 & 0 & 0 & 0 & 0 & 0 & 1,381 & 4,253 & 5,634 \\
\hline Total & 10,335 & 19,365 & 24,057 & sd & 11,168 & 25,490 & 41,159 & 79,913 & 211,478 \\
\hline
\end{tabular}

La Revista Universitaria del Caribe ingresó en febrero del 2017.

Los datos correspondientes del 2011 al 2013 fueron proporcionados por Sioux Cumming (2013).

\section{Ranking de revistas más consultadas en Lamjol}

En el análisis del comportamiento de las revistas científicas de El Salvador, Honduras y Nicaragua, alojadas en Latin American Jornual online (Lamjol), nos encontramos que la revista de URACCAN, Ciencia e Interculturalidad. tiene el primer lugar en descargas de revistas de universidades públicas, y el segundo lugar de las 49 revistas alojadas en el portal, en el período de agosto del 2015 a noviembre del 2018 (cuadro 9).

\section{Ranking de los artículos más consultados de la revista Ciencia e Interculturalidad en Latin American Jornal online (Lamjol), de agosto de 2015 a noviembre de 2018}

En el ranking de los artículos más consultados de la revista Ciencia e Interculturalidad en el portal de Lamjol, se evidencia que predominan en los primeros lugares las investigaciones vinculadas a la educación (cuadro 10). 
Cuadro No. 9: Ranking de revistas en Lamjol por descargas de artículos completos (agosto 2015 al 19 de nov 2018)

\begin{tabular}{|c|c|c|c|c|c|c|c|c|}
\hline \multirow[b]{2}{*}{$\#$} & \multirow[b]{2}{*}{ Título } & \multirow[b]{2}{*}{ Editorial } & \multirow[b]{2}{*}{ País } & \multicolumn{5}{|c|}{ Descargas de artículos } \\
\hline & & & & $\begin{array}{l}\text { Agosto a } \\
\text { dic } 2015\end{array}$ & 2016 & 2017 & 2018 & Total \\
\hline 1 & Revista de Derecho & $\begin{array}{l}\text { Universidad } \\
\text { Centroamericana, } \\
\text { Facultad de Ciencias } \\
\text { Jurídica }\end{array}$ & Nicaragua & 19145 & 54131 & 62395 & 97204 & 232,875 \\
\hline 2 & $\begin{array}{l}\text { Ciencia e } \\
\text { Interculturalidad }\end{array}$ & $\begin{array}{l}\text { Universidad de las } \\
\text { Regiones Autónomas } \\
\text { de la Costa Caribe } \\
\text { Nicaragüense - } \\
\text { URACCAN }\end{array}$ & Nicaragua & 11168 & 25490 & 39778 & 75660 & 152,096 \\
\hline 3 & $\begin{array}{l}\text { Revista Científica de } \\
\text { FAREM-Estelí }\end{array}$ & $\begin{array}{l}\text { Coordinación de } \\
\text { Investigación de la } \\
\text { FAREM-Estelí }\end{array}$ & Nicaragua & 670 & 10317 & 52589 & 84767 & 148,343 \\
\hline 4 & $\begin{array}{l}\text { Realidad: Revista de } \\
\text { Ciencias Sociales y } \\
\text { Humanidades }\end{array}$ & $\begin{array}{l}\text { Universidad } \\
\text { Centroamericana de } \\
\text { San Salvador (UCA) }\end{array}$ & El Salvador & 0 & 1341 & 13410 & 92476 & 107,227 \\
\hline 5 & $\begin{array}{l}\text { Paradigma: Revista } \\
\text { de investigación } \\
\text { educativa }\end{array}$ & $\begin{array}{l}\text { Instituto de } \\
\text { Investigación y } \\
\text { Evaluación Educativas } \\
\text { y Sociales }\end{array}$ & Honduras & 3341 & 8603 & 23379 & 67975 & 103,298 \\
\hline 6 & $\begin{array}{l}\text { La Revista de } \\
\text { Derecho }\end{array}$ & $\begin{array}{l}\text { Facultad de Ciencias } \\
\text { Jurídicas de la } \\
\text { Universidad Nacional } \\
\text { Autónoma de } \\
\text { Honduras }\end{array}$ & Honduras & 5232 & 14719 & 26066 & 43100 & 89,117 \\
\hline 7 & Ciencias Espaciales & $\begin{array}{l}\text { Universidad Nacional } \\
\text { Autónoma de } \\
\text { Honduras }\end{array}$ & Honduras & 3417 & 10982 & 18924 & 52716 & 86,039 \\
\hline 8 & $\begin{array}{l}\text { Nexo Revista } \\
\text { Científica }\end{array}$ & $\begin{array}{l}\text { Universidad Nacional } \\
\text { de Ingeniería (UNI) en } \\
\text { Managua }\end{array}$ & Nicaragua & 4590 & 11721 & 18746 & 48636 & 83,693 \\
\hline 9 & $\begin{array}{l}\text { Revista Policía y } \\
\text { Seguridad Pública }\end{array}$ & $\begin{array}{l}\text { Centro de } \\
\text { Investigación } \\
\text { Científica CINC-ANSP }\end{array}$ & El Salvador & 3668 & 11116 & 16358 & 43244 & 74,386 \\
\hline 10 & Wani & $\mathrm{BICU}$ & Nicaragua & 6736 & 15158 & 17796 & 33131 & 72,821 \\
\hline 11 & $\begin{array}{l}\text { Revista Ciencia y } \\
\text { Tecnología }\end{array}$ & $\begin{array}{l}\text { Dirección de } \\
\text { Investigación } \\
\text { Científica }\end{array}$ & Honduras & 4060 & 11715 & 14358 & 39209 & 69,342 \\
\hline
\end{tabular}




\begin{tabular}{|c|c|c|c|c|c|c|c|c|}
\hline \multirow[b]{2}{*}{$\#$} & \multirow[b]{2}{*}{ Título } & \multirow[b]{2}{*}{ Editorial } & \multirow[b]{2}{*}{ País } & \multicolumn{5}{|c|}{ Descargas de artículos } \\
\hline & & & & $\begin{array}{l}\text { Agosto a } \\
\text { dic } 2015\end{array}$ & 2016 & 2017 & 2018 & Total \\
\hline 12 & Realidad y Reflexión & $\begin{array}{l}\text { Universidad Francisco } \\
\text { Gavidia }\end{array}$ & El Salvador & 230 & 1788 & 14591 & 37010 & 53,619 \\
\hline 13 & Cultura de Paz & $\begin{array}{l}\text { Instituto de } \\
\text { Investigaciones y } \\
\text { Acción Social "Martin } \\
\text { Luther King" UPOLI }\end{array}$ & Nicaragua & 3285 & 12637 & 13674 & 22877 & 52,473 \\
\hline 14 & $\begin{array}{l}\text { Revista de } \\
\text { Museología "Kóot" }\end{array}$ & $\begin{array}{l}\text { Universidad } \\
\text { Tecnológica de El } \\
\text { Salvador Museo } \\
\text { universitario de } \\
\text { Antropología }\end{array}$ & El Salvador & 612 & 3065 & 5407 & 40865 & 49,949 \\
\hline 15 & Encuentro & $\begin{array}{l}\text { Division of Research } \\
\text { and Social Projection } \\
\text { (DIRINPRO) } \\
\text { Universidad } \\
\text { Centroamericana }\end{array}$ & Nicaragua & 1400 & 5415 & 11609 & 27719 & 46,143 \\
\hline 16 & Ceiba & $\begin{array}{l}\text { Escuela Agrícola } \\
\text { Panamericana } \\
\text { Zamorano }\end{array}$ & Honduras & 5004 & 12902 & 7964 & 15358 & 41,228 \\
\hline 17 & Portal de la Ciencia & $\begin{array}{l}\text { Dirección de } \\
\text { Investigación } \\
\text { Científica }\end{array}$ & Honduras & 1243 & 5161 & 8645 & 26015 & 41,064 \\
\hline 18 & $\begin{array}{l}\text { Universidad y } \\
\text { Ciencia }\end{array}$ & $\begin{array}{l}\text { http://www.unan.edu. } \\
\text { ni/ }\end{array}$ & Nicaragua & 668 & 2094 & 5640 & 29308 & 37,710 \\
\hline 19 & $\begin{array}{l}\text { Economía y } \\
\text { Administración } \\
(E \& A)\end{array}$ & $\begin{array}{l}\text { Economía y } \\
\text { Administración } \\
(\text { E\&A) es editada } \\
\text { por el Instituto de } \\
\text { Investigaciones } \\
\text { Económicas }\end{array}$ & Honduras & 26 & 425 & 5483 & 28728 & 34,662 \\
\hline 20 & $\begin{array}{l}\text { REICE: Revista } \\
\text { Electrónica de } \\
\text { Investigación en } \\
\text { Ciencias Económicas }\end{array}$ & UNAN-Managua & Nicaragua & 1295 & 2896 & 6348 & 17654 & 28,193 \\
\hline 21 & Diá-logos & $\begin{array}{l}\text { Universidad Don } \\
\text { Bosco }\end{array}$ & El Salvador & 202 & 1630 & 5461 & 19190 & 26,483 \\
\hline 22 & Teoría y Praxis & $\begin{array}{l}\text { Facultad de Ciencias } \\
\text { y Humanidades de } \\
\text { la Universidad Don } \\
\text { Bosco de El Salvador }\end{array}$ & El Salvador & 1513 & 2477 & 4956 & 16914 & 25,860 \\
\hline
\end{tabular}




\begin{tabular}{|c|c|c|c|c|c|c|c|c|}
\hline \multirow[b]{2}{*}{$\#$} & \multirow[b]{2}{*}{ Título } & \multirow[b]{2}{*}{ Editorial } & \multirow[b]{2}{*}{ País } & \multicolumn{5}{|c|}{ Descargas de artículos } \\
\hline & & & & $\begin{array}{l}\text { Agosto a } \\
\text { dic } 2015\end{array}$ & 2016 & 2017 & 2018 & Total \\
\hline 23 & $\begin{array}{l}\text { Innovare: Revista de } \\
\text { ciencia y tecnología }\end{array}$ & $\begin{array}{l}\text { Universitario UNITEC/ } \\
\text { CEUTEC }\end{array}$ & Honduras & 19 & 1048 & 2766 & 18609 & 22,442 \\
\hline 24 & $\begin{array}{l}\text { Población y } \\
\text { Desarrollo - } \\
\text { Argonautas y cami- } \\
\text { nantes }\end{array}$ & $\begin{array}{l}\text { Universidad Nacional } \\
\text { Autónoma De } \\
\text { Honduras }\end{array}$ & Honduras & 1534 & 4754 & 3868 & 7059 & 17,215 \\
\hline 25 & Synapsis & $\begin{array}{l}\text { Universitario de } \\
\text { Neurociencias }\end{array}$ & Honduras & 1548 & 3999 & 4107 & 7440 & 17,094 \\
\hline 26 & La Calera & $\begin{array}{l}\text { Universidad Nacional } \\
\text { Agraria (UNA) }\end{array}$ & Nicaragua & 1390 & 3850 & 3367 & 7947 & 16,554 \\
\hline 27 & $\begin{array}{l}\text { Revista Médica de } \\
\text { los Postgrados de } \\
\text { Medicina }\end{array}$ & UNAH & Honduras & 306 & 13313 & 621 & 1584 & 15,824 \\
\hline 28 & $\begin{array}{l}\text { Universitas (León): } \\
\text { Revista Científica de } \\
\text { la UNAN León }\end{array}$ & UNAN-León & Nicaragua & 402 & 1445 & 2268 & 5759 & 9,874 \\
\hline 29 & $\begin{array}{l}\text { Revista Humanismo } \\
\text { y Cambio Social }\end{array}$ & $\begin{array}{l}\text { Facultad de } \\
\text { Humanidades y } \\
\text { Ciencias Jurídicas, } \\
\text { UNAN }\end{array}$ & Nicaragua & 0 & 0 & 2306 & 7270 & 9,576 \\
\hline 30 & $\begin{array}{l}\text { Ciencia, Cultura y } \\
\text { Sociedad }\end{array}$ & $\begin{array}{l}\text { Universidad } \\
\text { Evangélica de El } \\
\text { Salvador (UEES) }\end{array}$ & El Salvador & & 339 & 1153 & 8036 & 9,528 \\
\hline 31 & $\begin{array}{l}\text { Acta Pediátrica } \\
\text { Hondureña }\end{array}$ & $\begin{array}{l}\text { Escuela Universitaria } \\
\text { de las Ciencias de la } \\
\text { Salud, EUCS, UNAH-VS }\end{array}$ & Honduras & 77 & 1791 & 2918 & 4169 & 8,955 \\
\hline 32 & $\begin{array}{l}\text { Producción } \\
\text { Agropecuaria } \\
\text { y Desarrollo } \\
\text { Sostenible } \\
\end{array}$ & $\begin{array}{l}\text { Universidad Católica } \\
\text { de El Salvador }\end{array}$ & El Salvador & 0 & 0 & 1621 & 6684 & 8,305 \\
\hline 33 & $\begin{array}{l}\text { Crea Ciencia Revista } \\
\text { Científica }\end{array}$ & $\begin{array}{l}\text { Universidad } \\
\text { Evangélica de El } \\
\text { Salvador }\end{array}$ & El Salvador & 0 & 308 & 1835 & 5081 & 7,224 \\
\hline 34 & AKADEMOS & $\begin{array}{l}\text { Red Docencia- } \\
\text { Investigación, } \\
\text { Universidad Dr. José } \\
\text { Matías Delgado }\end{array}$ & El Salvador & 0 & 0 & 1187 & 5773 & 6,960 \\
\hline
\end{tabular}




\begin{tabular}{|c|c|c|c|c|c|c|c|c|}
\hline \multirow[b]{2}{*}{$\#$} & \multirow[b]{2}{*}{ Título } & \multirow[b]{2}{*}{ Editorial } & \multirow[b]{2}{*}{ País } & \multicolumn{5}{|c|}{ Descargas de artículos } \\
\hline & & & & $\begin{array}{l}\text { Agosto a } \\
\text { dic } 2015\end{array}$ & 2016 & 2017 & 2018 & Total \\
\hline 35 & $\begin{array}{l}\text { Revista } \\
\text { Iberoamericana } \\
\text { de Bioeconomía y } \\
\text { Cambio Climático }\end{array}$ & $\begin{array}{l}\text { Universidad Nacional } \\
\text { Autónoma de } \\
\text { Nicaragua, León }\end{array}$ & Nicaragua & 65 & 790 & 802 & 5235 & 6,892 \\
\hline 36 & $\begin{array}{l}\text { Revista UNAH } \\
\text { INNOV@ }\end{array}$ & $\begin{array}{l}\text { Universidad Nacional } \\
\text { Autónoma de } \\
\text { Honduras, UNAH }\end{array}$ & Honduras & 0 & 1116 & 1354 & 4129 & 6,599 \\
\hline 37 & $\begin{array}{l}\text { Revista Científica } \\
\text { de la Escuela } \\
\text { Universitaria de las } \\
\text { Ciencias de la Salud }\end{array}$ & $\begin{array}{l}\text { Universidad Nacional } \\
\text { Autónoma de } \\
\text { Honduras- en el Valle } \\
\text { de Sula }\end{array}$ & Honduras & 0 & 313 & 1626 & 3716 & 5,655 \\
\hline 38 & $\begin{array}{l}\text { Revista Universitaria } \\
\text { del Caribe }\end{array}$ & $\begin{array}{l}\text { Universidad de las } \\
\text { Regiones Autónomas } \\
\text { de la Costa Caribe } \\
\text { Nicaragüense } \\
\text { (URACCAN) }\end{array}$ & Nicaragua & 0 & 0 & 1381 & 4253 & 5,634 \\
\hline 39 & $\begin{array}{l}\text { FHIA. Programa de } \\
\text { Hortalizas }\end{array}$ & $\begin{array}{l}\text { Fundación Hondureña } \\
\text { de Investigación } \\
\text { Agrícola, Programa de } \\
\text { Hortalizas }\end{array}$ & Honduras & 674 & 1505 & 1191 & 1972 & 5,342 \\
\hline 40 & Entorno & $\begin{array}{l}\text { Universidad } \\
\text { Tecnológica de El } \\
\text { Salvador. } \\
\end{array}$ & El Salvador & 0 & 0 & 0 & 4698 & 4,698 \\
\hline 41 & $\begin{array}{l}\text { Revista Torreón } \\
\text { Universitario }\end{array}$ & $\begin{array}{l}\text { Facultad Regional } \\
\text { Multidisciplinaria de } \\
\text { Carazo }\end{array}$ & Nicaragua & 0 & 0 & 495 & 4038 & 4,533 \\
\hline 42 & $\begin{array}{l}\text { Revista Perspectivas } \\
\text { del Desarrollo }\end{array}$ & $\begin{array}{l}\text { Universidad Nacional } \\
\text { Autónoma de } \\
\text { Honduras }\end{array}$ & Honduras & 152 & 1438 & 1158 & 1377 & 4,125 \\
\hline 43 & Realidad Empresarial & $\begin{array}{l}\text { Universidad } \\
\text { Centroamericana José } \\
\text { Simeón Cañas }\end{array}$ & El Salvador & 0 & 0 & 0 & 4082 & 4,082 \\
\hline 44 & $\begin{array}{l}\text { Conocimiento } \\
\text { Educativo }\end{array}$ & $\begin{array}{l}\text { Universidad Católica } \\
\text { de El Salvador }\end{array}$ & El Salvador & 0 & 0 & 0 & 3992 & 3,992 \\
\hline 45 & $\begin{array}{l}\text { Raíces - Revista } \\
\text { Nicaragüense de } \\
\text { Antropología }\end{array}$ & $\begin{array}{l}\text { Universidad Nacional } \\
\text { Autónoma de } \\
\text { Nicaragua, UNAN - } \\
\text { Managua }\end{array}$ & Nicaragua & 0 & 0 & 635 & 2022 & 2,657 \\
\hline
\end{tabular}




\begin{tabular}{|c|c|c|c|c|c|c|c|c|}
\hline \multirow[b]{2}{*}{$\#$} & \multirow[b]{2}{*}{ Título } & \multirow[b]{2}{*}{ Editorial } & \multirow[b]{2}{*}{ País } & \multicolumn{5}{|c|}{ Descargas de artículos } \\
\hline & & & & $\begin{array}{l}\text { Agosto a } \\
\text { dic } 2015\end{array}$ & 2016 & 2017 & 2018 & Total \\
\hline 46 & $\begin{array}{l}\text { Revista de } \\
\text { Humanidades y } \\
\text { Ciencias Sociales }\end{array}$ & $\begin{array}{l}\text { Centro Nacional de } \\
\text { Investigaciones en } \\
\text { Ciencias Sociales } \\
\text { y Humanidades } \\
\text { (CENICSH) }\end{array}$ & El Salvador & $\mathrm{O}$ & $\mathrm{O}$ & 0 & 303 & 303 \\
\hline 47 & $\begin{array}{l}\text { ALERTA: Revista } \\
\text { Científica del } \\
\text { Instituto Nacional de } \\
\text { Salud }\end{array}$ & $\begin{array}{l}\text { Instituto Nacional de } \\
\text { Salud, Ministerio de } \\
\text { Salud de El Salvador }\end{array}$ & El Salvador & 0 & $\mathrm{O}$ & $\mathrm{O}$ & 236 & 236 \\
\hline 48 & $\begin{array}{l}\text { Revista Electrónica } \\
\text { de Conocimientos, } \\
\text { Saberes y Prácticas }\end{array}$ & $\begin{array}{l}\text { Comunidad } \\
\text { Matemática de } \\
\text { la Costa Caribe } \\
\text { Nicaragüense } \\
\text { (CMCCN) }\end{array}$ & Nicaragua & 0 & $\mathrm{O}$ & $\mathrm{O}$ & 63 & 63 \\
\hline 49 & $\begin{array}{l}\text { Revista de entrena- } \\
\text { miento }\end{array}$ & UNAH & Honduras & $\mathrm{O}$ & $\mathrm{O}$ & 1 & 40 & 41 \\
\hline
\end{tabular}

Fuente: Elaboración propia en base a datos de descargas anuales proporcionados por Ernesto Correa, del equipo de Lamjol.

Cuadro No. 10: Ranking de los artículos más consultados de la revista Ciencia e Interculturalidad en Latin American Jornal online (Lamjol), de agosto de 2015 a noviembre de 2018

\begin{tabular}{|c|c|c|c|}
\hline No. & Artículo & Número & $\begin{array}{c}\text { Descargas } \\
\text { pdf }\end{array}$ \\
\hline 1 & $\begin{array}{l}\text { Factores que influyen en el proceso de Enseñanza-aprendizaje en el área } \\
\text { español como segunda lengua, en quinto y sexto grado en la modalidad } \\
\text { de multigrado en la escuela Bilingüe: "Enmanuel". Año } 2007 \text { - 2008, Rosita, } \\
\text { RAAN. Autores: Isabel Lackwood Bustillo, Zoraida Ruíz Rivera, Verónica } \\
\text { Valdivia. }\end{array}$ & $\begin{array}{l}\text { Vol. 2, } \\
\text { Núm. } 2 \\
\text { (2008) }\end{array}$ & 42,052 \\
\hline 2 & $\begin{array}{l}\text { La desintegración familiar y el aprendizaje en la niñez de iv grado. Autores: } \\
\text { María Estela Vargas Tess, Nalia Rosales Cunningham, Argentina García } \\
\text { Solórzano. }\end{array}$ & $\begin{array}{l}\text { Vol. 1, } \\
\text { Núm. } 1 \\
(2008)\end{array}$ & 12,298 \\
\hline 3 & $\begin{array}{l}\text { Creencias y costumbres tradicionales del pueblo indígena mískitu de } \\
\text { Kahkabila. Autores: Lina Carlos Grádiz, Sonia Garth, Paula Ingram. }\end{array}$ & $\begin{array}{l}\text { Vol. 5, } \\
\text { Núm. } 2 \\
\text { (2009) }\end{array}$ & 8,594 \\
\hline 4 & $\begin{array}{l}\text { Influencia de las fases lunares sobre el rendimiento del maíz (Zea mays } \\
\text { variedad nb6). Autores: Larry Flores Martínez, Féliz Meléndez Mejía, Gladys } \\
\text { Luna Bello, Eliseo González Lazo. }\end{array}$ & $\begin{array}{l}\text { Vol. 10, } \\
\text { Núm. } 1 \\
(2012)\end{array}$ & 8,258 \\
\hline 5 & $\begin{array}{l}\text { Influencia de los factores socioeconómicos en la deserción estudiantil } \\
\text { de la carrera de Ciencias Sociales. Autores: Dominga Del Socorro Sevilla } \\
\text { Núñez, Víctor Adrián Puerta Chavarría, Jacoba Dávila Molina. }\end{array}$ & $\begin{array}{l}\text { Vol. 6, } \\
\text { Núm. } 1 \\
\text { (2010) }\end{array}$ & 7,082 \\
\hline
\end{tabular}




\begin{tabular}{|c|c|c|c|}
\hline No. & Artículo & Número & $\begin{array}{c}\text { Descargas } \\
\text { pdf }\end{array}$ \\
\hline 6 & $\begin{array}{l}\text { Factores pedagógicos y socioeconómicos que inciden en el proceso en- } \\
\text { señanza -aprendizaje en la modalidad de multigrado bilingüe: idiomas } \\
\text { sumu-mayangna, en la comunidad de "Fruta de Pan", segundo semestre } \\
2007 \text { y primer semestre del } 2008 \text {. Autores: Daysi Lackwood Bustillo, Judith } \\
\text { Edith Frank Pedro, Julia Argüello Mendieta. }\end{array}$ & $\begin{array}{l}\text { Vol. } 2 \\
\text { Núm. } 2 \\
(2008)\end{array}$ & 4,496 \\
\hline 7 & $\begin{array}{l}\text { Diagnóstico biofísico y socioeconómico de la cuenca Bilwi Tingni, Puerto } \\
\text { Cabezas, RAAN. Autores: Ulises Cordón Suárez, Wilfredo Johnson, Enrique } \\
\text { Cordón Suárez. }\end{array}$ & $\begin{array}{l}\text { Vol. } 2 \\
\text { Núm. } 2 \\
(2008)\end{array}$ & 3,548 \\
\hline 8 & $\begin{array}{l}\text { Medios audiovisuales utilizados en la enseñanza en la carrera de zootecnia. } \\
\text { Autores: Consuelo Lizeth Blandón Jirón, Claribel Del Rosario Castillo Úbeda. }\end{array}$ & $\begin{array}{l}\text { Vol. 5, } \\
\text { Núm. } 2 \\
\text { (2009) }\end{array}$ & 2,213 \\
\hline 9 & $\begin{array}{l}\text { Los recursos didácticos en la enseñanza y aprendizaje del inglés: una } \\
\text { aproximación exploratoria. Autores: Claudio Díaz Larenas, Karen Aguilera } \\
\text { Chamorro, Romina Fuentes Concha, Paula Pérez Becerra. }\end{array}$ & $\begin{array}{l}\text { Vol. 13, } \\
\text { Núm. } 2 \\
(2013)\end{array}$ & 2,074 \\
\hline 10 & $\begin{array}{l}\text { Etno-matemática en indígenas ulwas, comunidad de Karawala, Región } \\
\text { Autónoma Atlántico Sur, Nicaragua. Autores: Minerva Soza Valverde, Alba } \\
\text { Luz Dávila Espinoza. }\end{array}$ & $\begin{array}{l}\text { Vol. 11, } \\
\text { Núm. } 2 \\
(2012)\end{array}$ & 1,943 \\
\hline 11 & $\begin{array}{l}\text { Sistema productivo de la comunidad indígena miskita de Tasbarraya, } \\
\text { RAAN. Autores: Minerva Soza Valverde, Alba Luz Dávila Espinoza. }\end{array}$ & $\begin{array}{l}\text { Vol. 13, } \\
\text { Núm. } 2 \\
\text { (2013) }\end{array}$ & 1,868 \\
\hline 12 & $\begin{array}{l}\text { Factores que inciden en el proceso de enseñanza - aprendizaje del espa- } \\
\text { ñol como segunda lengua (L2), segundo grado, escuela "Santo Tomás de } \\
\text { Umbra", segundo semestre del año 2007. Autores: Leandro Pekitle Pedro, } \\
\text { Hernacio Pedro Maibeth, Eloy Frank Gómez. }\end{array}$ & $\begin{array}{l}\text { Vol. } 2 \\
\text { Núm. } 2 \\
(2008)\end{array}$ & 1,377 \\
\hline 13 & $\begin{array}{l}\text { Tipos de enraizadores en varetas de (Theobroma cacao), comunidad } \\
\text { Carao. Siuna, 2011. Autores: Freddy Francisco Cordero Rivera, Oscar } \\
\text { Montalván Castellón, Oscar Flores Pérez. }\end{array}$ & $\begin{array}{l}\text { Vol. 14, } \\
\text { Núm. } 1 \\
\text { (2014) }\end{array}$ & 1,371 \\
\hline 14 & $\begin{array}{l}\text { Rendimiento de dos variedades mejoradas de frijol, sembrados al voleo } \\
\text { y al espeque, en Moss Pam, Waspam, rio Coco. Autores: Sankara Keith } \\
\text { Narvaez Ismale, Hector R Marchena Williams, William J Watler Reyes, } \\
\text { Enrique Cordón Suárez. }\end{array}$ & $\begin{array}{l}\text { Vol. 9, } \\
\text { Núm. } 2 \\
\text { (2011) }\end{array}$ & 1,345 \\
\hline 15 & $\begin{array}{l}\text { Educación intercultural bilingüe en Argentina: un panorama actual. } \\
\text { Autores: Ana Carolina Hecht. }\end{array}$ & $\begin{array}{l}\text { Vol. 16, } \\
\text { Núm. } 1 \\
(2015) \\
\end{array}$ & 1,224 \\
\hline 16 & $\begin{array}{l}\text { La invasión a bahía de Cochinos, Cuba, desde la mirada de la población } \\
\text { de Bilwi, Puerto Cabezas, Nicaragua. Autores: Albert St'Clair H, Mercedes } \\
\text { Tinoco Espinoza. }\end{array}$ & $\begin{array}{l}\text { Vol. 7, } \\
\text { Núm. } 2 \\
(2010)\end{array}$ & 1,159 \\
\hline 17 & $\begin{array}{l}\text { Economía indígena en la comunidad Sikilta, municipio de Siuna, RAAN. } \\
\text { Autores: Pío Alejandro García Izaguirre, Saida De los Ángeles Argüello } \\
\text { Mendieta. }\end{array}$ & $\begin{array}{l}\text { Vol. 8, } \\
\text { Núm. } 1 \\
(2011)\end{array}$ & 1,094 \\
\hline
\end{tabular}




\begin{tabular}{|c|c|c|c|}
\hline No. & Artículo & Número & $\begin{array}{c}\text { Descargas } \\
\text { pdf }\end{array}$ \\
\hline 18 & $\begin{array}{l}\text { Métodos de enseñanza de física, modalidad a distancia en el Instituto } \\
\text { Sabatino “Esperanza”, municipio de Siuna. Autores: Marta Nidia Tinoco } \\
\text { Méndez, Reina Isabel Hernández Herrera. }\end{array}$ & $\begin{array}{l}\text { Vol. 11, } \\
\text { Núm. } 2 \\
(2012)\end{array}$ & 1,084 \\
\hline 19 & $\begin{array}{l}\text { Administración del proyecto "Desarrollo de capacidades humanas", me- } \\
\text { diante las técnicas administrativas CPM Y PERT, URACCAN - Siuna, } 2012 . \\
\text { Autores: Yader Antonio Ordoñez Aguilar, Eddy Alberto Zamora Díaz, Javier } \\
\text { Osmar Artola García. }\end{array}$ & $\begin{array}{l}\text { Vol. 14, } \\
\text { Núm. } 1 \\
\text { (2014) }\end{array}$ & 1072 \\
\hline 20 & $\begin{array}{l}\text { Estilos de aprendizajes y enfoques de enseñanza, carrera de ingenie- } \\
\text { ría agroforestal. Autores: Ariel Domingo Chavarría Vigil, Sergio Genaro } \\
\text { Rodríguez Ruíz. }\end{array}$ & $\begin{array}{l}\text { Vol. 5, } \\
\text { Núm. } 2 \\
\text { (2009) }\end{array}$ & 1065 \\
\hline
\end{tabular}

\section{Revistas de URACCAN en el Portal de Revistas de Nicaragua}

$\mathrm{Al}$ analizar el comportamiento de las revistas de URACCAN en el Portal de Revistas de Nicaragua en el período 2012 a octubre del 2018, nos encontramos que ambas revistas acumulan un total de 35,308 descargas de artículos en pdf. Por revista, Ciencia e Interculturalidad tiene un total de 29,773 descargas de artículos completos y 27,559 para revisar resúmenes; por su parte, la Revista Universitaria del Caribe, en el período febrero 2017 a octubre 2018, tiene 5,535 descargas de artículos completos y 8,740 visitas para revisar resúmenes (cuadro 11).

Cuadro No. 11: Resumen de visitas a revistas de URACCAN en el Portal de Revistas de Nicaragua

\begin{tabular}{|l|l|l|l|l|}
\hline \multirow{2}{*}{ Revista } & \multicolumn{4}{c|}{ Número y tipo de consultas } \\
\cline { 2 - 5 } & $\begin{array}{c}\text { Leer } \\
\text { resumen }\end{array}$ & $\%$ & $\begin{array}{c}\text { Descargar } \\
\text { pdf }\end{array}$ & $\%$ \\
\hline Ciencia e Interculturalidad & 27,559 & 76 & 29,773 & 84.3 \\
\hline 2012 a noviembre del 2013 & 12,522 & & 13,881 & \\
\hline 2014 a octubre del 2018 & 15,037 & & 15,892 & \\
\hline & & & & 15.7 \\
\hline Revista Universitaria del Caribe & 8,740 & 24 & 5,535 & \\
\hline $\begin{array}{l}\text { Febrero del 2017 a octubre del } \\
2018\end{array}$ & 8,740 & & 5,535 & 100 \\
\hline Total & 36,299 & 100 & 35,308 & \\
\hline
\end{tabular}




\section{Artículos más leídos de la revista Ciencia e Interculturalidad en el Portal de Revistas de Nicaragua}

En el ranking de los artículos más descargados de la revista Ciencia e Interculturalidad en el Portal de Revistas de Nicaragua, para el período 2014 al 30 de octubre 2018, se evidencia que los artículos más descargados corresponden a la actividad agropecuaria y educación (cuadro 12).

\section{Artículos más leídos de la Revista Universitaria del Caribe en el Portal de Revistas de Nicaragua}

En el ranking de los artículos más descargados de la Revista Universitaria del Caribe en el Portal de Revistas de Nicaragua, para el período febrero 2017 al 30 de octubre 2018, se evidencia que los artículos más descargados corresponden a la actividad agropecuaria seguidos de los de educación (cuadro 13).

Cuadro No. 12: Ranking de artículos más leídos de Ciencia e Interculturalidad en el Portal de Revistas de Nicaragua, 2014 a octubre 2018

\begin{tabular}{|c|c|c|c|c|}
\hline$\#$ & Título & Volumen & Fecha pub & $\begin{array}{c}\text { Descarga } \\
\text { pdf }\end{array}$ \\
\hline 1 & $\begin{array}{l}\text { Influencia de las fases lunares sobre el rendimiento del } \\
\text { maíz (Zea mays variedad NB6). Autores: Larry Flores } \\
\text { Martínez, Féliz Meléndez Mejía, Gladys Luna Bello, Eliseo } \\
\text { González Lazo. }\end{array}$ & $\begin{array}{l}\text { Vol. } 10 \\
\text { Núm. } 1 \\
\text { (2012) }\end{array}$ & 17/10/2012 & 731 \\
\hline 2 & $\begin{array}{l}\text { Ranking de artículos más leídos de la URACCAN publi- } \\
\text { cados en sus revistas electrónicas con acceso abierto. } \\
\text { Autores: Perera Lumbí Juan francisco. }\end{array}$ & $\begin{array}{l}\text { Vol. } 13 \\
\text { Núm. } 2 \\
\text { (2013) }\end{array}$ & $19 / 12 / 2013$ & 458 \\
\hline 3 & $\begin{array}{l}\text { Comportamiento agronómico del cultivo del plátano, } \\
\text { variedad curare enano en Sandy Bay Costa Caribe Norte } \\
\text { de Nicaragua. Autores: Karen Yaskara Castellón Muller, } \\
\text { William Benjamin Pineda, Enrique Cordón Suárez. }\end{array}$ & $\begin{array}{l}\text { Vol. } 21 \\
\text { Núm. } 2 \\
(2017)\end{array}$ & 20/02/2018 & 439 \\
\hline 4 & $\begin{array}{l}\text { Administración del proyecto de desarrollo de capacida- } \\
\text { des humanas, mediante las técnicas administrativas CPM } \\
\text { y PERT, URACCAN Siuna, 2012. Autores: Yader Antonio } \\
\text { Ordoñez Aguilar, Eddy Alberto Zamora Díaz, Javier } \\
\text { Osmar Artola García. }\end{array}$ & $\begin{array}{l}\text { Vol. } \\
\text { Núm. } 1 \\
\text { (2014) }\end{array}$ & 05/09/2014 & 429 \\
\hline 5 & $\begin{array}{l}\text { Comprensión del aprendizaje de la parábola en undé- } \\
\text { cimo grado aplicando el modelo de Van Hiele. Autores: } \\
\text { Marvin Alejandro Gaitán Hernández, Melvin Antonio } \\
\text { Lacayo Robles, William Oswaldo Flores López. }\end{array}$ & $\begin{array}{l}\text { Vol. } 15 \\
\text { Núm. } 2 \\
(2014)\end{array}$ & $24 / 04 / 2015$ & 344 \\
\hline
\end{tabular}




\begin{tabular}{|c|c|c|c|c|}
\hline$\#$ & Título & Volumen & Fecha pub & $\begin{array}{c}\text { Descarga } \\
\text { pdf }\end{array}$ \\
\hline 6 & $\begin{array}{l}\text { Situación de la evaluación del desempeño docente en } \\
\text { la URACCAN Recinto Las Minas, 2007-2008. Autores: Noel } \\
\text { Altamirano Lumbí, Iris Del Rosario López Aburto, Maribel } \\
\text { Duriéz González. }\end{array}$ & $\begin{array}{l}\text { Vol. } 6 \\
\text { Núm. } 1 \\
(2010)\end{array}$ & 24/01/2012 & 308 \\
\hline 7 & $\begin{array}{l}\text { Sistema productivo de la comunidad indígena miskita } \\
\text { de Tasbarraya, RAAN. Autores: Minerva Soza Valverde, } \\
\text { Alba Luz Dávila Espinoza. }\end{array}$ & $\begin{array}{l}\text { Vol. } 13 \\
\text { Núm. } 2 \\
(2013)\end{array}$ & 19/12/2013 & 298 \\
\hline 8 & $\begin{array}{l}\text { Participación de las mujeres en las unidades producti- } \\
\text { vas familiares rurales, Rosita, RAAN. Autores: Sonia Del } \\
\text { Carmen García Aguilar, Argentina García Solórzano. }\end{array}$ & $\begin{array}{l}\text { Vol. } 10 \\
\text { Núm. } 1 \\
(2012)\end{array}$ & 17/10/2012 & 296 \\
\hline 9 & $\begin{array}{l}\text { Educación Intercultural Bilingüe en Argentina: un pano- } \\
\text { rama actual. Autores: Ana Carolina Hecht. }\end{array}$ & $\begin{array}{l}\text { Vol. } 16 \\
\text { Núm. } 1 \\
(2015) \\
\end{array}$ & 27/01/2016 & 284 \\
\hline 10 & $\begin{array}{l}\text { Elementos metodológicos que inciden en la enseñanza } \\
\text { "aprendizaje del español en estudiantes de primer gra- } \\
\text { do, Bilwi, RAAN. Autores: Petronila Bello Fenly, Maritza } \\
\text { Gutiérrez Guillermo, Argentina García Solórzano. }\end{array}$ & $\begin{array}{l}\text { Vol. } 10 \\
\text { Núm. } 1 \\
(2012)\end{array}$ & $17 / 10 / 2012$ & 281 \\
\hline 11 & $\begin{array}{l}\text { Efectividad de un biofertilizante foliar sobre el cultivo } \\
\text { de frijol común (Phaseolus vulgaris), Bluefields, R.A.A.S. } \\
\text { Autores: Yader Mejía Bermúdez, Mario Álvarez Arroyo, } \\
\text { Gladys Luna Bello. }\end{array}$ & $\begin{array}{l}\text { Vol. } 8 \\
\text { Núm. } 1 \\
(2011)\end{array}$ & $12 / 01 / 2012$ & 276 \\
\hline 12 & $\begin{array}{l}\text { Tipos de enraizadores en varetas de Ttheobroma cacao), } \\
\text { comunidad carao. Siuna, 2011. Autores: Freddy Francisco } \\
\text { Cordero Rivera, Oscar Montalván Castellón, Oscar Flores } \\
\text { Pérez. }\end{array}$ & $\begin{array}{l}\text { Vol. } 14 \\
\text { Núm.1 } \\
(2014)\end{array}$ & 05/09/2014 & 276 \\
\hline 13 & $\begin{array}{l}\text { Atención en Salud a las Personas de la Tercera Edad en } \\
\text { el Modelo de Salud Intercultural de MASI RAAN. Autores: } \\
\text { Manuel Salas Flores. }\end{array}$ & $\begin{array}{l}\text { Vol. } 15 \\
\text { Núm. } 2 \\
(2014)\end{array}$ & 24/04/2015 & 275 \\
\hline 14 & $\begin{array}{l}10 \text { años de historia fundacional de la URACCAN Siuna- } \\
\text { Las Minas. Autores: Fredy Leonel Valiente Contreras, } \\
\text { Víctor Manuel Del Cid Lucero. }\end{array}$ & $\begin{array}{l}\text { Vol. } 10 \\
\text { Núm. } 1 \\
(2012)\end{array}$ & $17 / 10 / 2012$ & 238 \\
\hline 15 & $\begin{array}{l}\text { Oferta académica de la URACCAN en el nivel de grado } \\
\text { para el quinquenio 2014-2018. Autores: Letisia Castillo } \\
\text { Gómez, Angélica Leonor Ruíz Calderón, Marlon Antonio } \\
\text { Peralta Mendoza, Alba Luz Dávila, Ivania Simons, Juan } \\
\text { Francisco Perera Lumbí. }\end{array}$ & $\begin{array}{l}\text { Vol. } 13 \\
\text { Núm. } 2 \\
(2013)\end{array}$ & $19 / 12 / 2013$ & 227 \\
\hline 16 & $\begin{array}{l}\text { Aborto terapéutico en Nicaragua y el Salvador, la morta- } \\
\text { lidad materna y los objetivos del milenio. Autores: Adlin } \\
\text { Nerissa Bacon Bolaños. }\end{array}$ & $\begin{array}{l}\text { Vol. } 12 \\
\text { Núm. } 1 \\
(2013)\end{array}$ & 15/10/2013 & 222 \\
\hline
\end{tabular}




\begin{tabular}{|c|c|c|c|c|}
\hline$\#$ & Título & Volumen & Fecha pub & $\begin{array}{c}\text { Descarga } \\
\text { pdf }\end{array}$ \\
\hline 17 & $\begin{array}{l}\text { Residuos de camarón siete barbas como abono orgáni- } \\
\text { co en el cultivo de tomate. Autores: Xiomara Treminio } \\
\text { Luna, Jordi Bartolomé F. }\end{array}$ & $\begin{array}{l}\text { Vol. } 15 \\
\text { Núm. } 2 \\
\text { (2014) }\end{array}$ & 24/04/2015 & 209 \\
\hline 18 & $\begin{array}{l}\text { Etno-matemática en indígenas Ulwas, comunidad de } \\
\text { Karawala, Región Autónoma Atlántico Sur, Nicaragua. } \\
\text { Autores: Minerva Soza Valverde, Alba Luz Dávila } \\
\text { Espinoza. }\end{array}$ & $\begin{array}{l}\text { Vol. } 11 \\
\text { Núm. } 2 \\
\text { (2012) }\end{array}$ & $14 / 02 / 2013$ & 200 \\
\hline 19 & $\begin{array}{l}\text { Enseñanza de la geometría en segundo año de educa- } \\
\text { ción secundaria bajo el enfoque de competencias. Una } \\
\text { Propuesta metodológica basada en competencias para } \\
\text { la enseñanza de la geometría. Autores: Silguian Yamileth } \\
\text { Gutiérrez M, Eugenio Casimiro López Mairena. }\end{array}$ & $\begin{array}{l}\text { Vol. } 6 \\
\text { Núm.1 } \\
(2010)\end{array}$ & 24/01/2012 & 189 \\
\hline 20 & $\begin{array}{l}\text { Efecto de caldo sulfocálicico en el control de garrapa- } \\
\text { tas del ganado bovino. Autores: Danny Antipa Rivera, } \\
\text { Osvaldo Antonio Solano, Arsenio López Borge. }\end{array}$ & $\begin{array}{l}\text { Vol. } 15 \\
\text { Núm.2 } \\
\text { (2014) }\end{array}$ & 24/04/2015 & 184 \\
\hline
\end{tabular}

Cuadro No. 13: Ranking de artículos más leído de Revista Universitaria del Caribe en el Portal de Revistas de Nicaragua, febrero 2017 a octubre 2018

\begin{tabular}{|c|c|c|c|c|}
\hline$\#$ & Título & Volumen & Fecha pub & $\begin{array}{c}\text { Descargas } \\
\text { PDF }\end{array}$ \\
\hline 1 & $\begin{array}{l}\text { Percepción y prácticas de atención del Grisi siknis de } \\
\text { la comunidad de krin krin, Waspam, río Coco. Autores: } \\
\text { Cipriano Henríquez Levas, Norbeto Chacón Mendoza, } \\
\text { Serafina Espinoza Blanco. }\end{array}$ & $\begin{array}{l}\text { Vol. } 16 \\
\text { Núm. } 1 \\
(2016)\end{array}$ & 31/01/2017 & 268 \\
\hline 2 & $\begin{array}{l}\text { Los efectos de la luna en la producción agropecuaria. } \\
\text { Autores: Aura Danelia Vásquez Cabrera, Jaritza Maquiel } \\
\text { Narváez Gago, Wilson Antonio Calero Borge. }\end{array}$ & $\begin{array}{l}\text { Vol. } 13 \\
\text { Núm. } 2 \\
(2014)\end{array}$ & $10 / 07 / 2015$ & 242 \\
\hline 3 & $\begin{array}{l}\text { Construcción de instrumentos de evaluación del desem- } \\
\text { peño docente universitario desde una perspectiva cua- } \\
\text { litativa. Autores: Tonys Romero Díaz, Almudena Martínez } \\
\text { Gimeno. }\end{array}$ & $\begin{array}{l}\text { Vol. } 18 \\
\text { Núm. } 1 \\
(2017)\end{array}$ & $25 / 08 / 2017$ & 235 \\
\hline 4 & $\begin{array}{l}\text { Los laboratorios naturales un espacio vivo para la for- } \\
\text { mación integral del estudiantado de la Universidad } \\
\text { Comunitaria Intercultural, URACCAN. Autores: Oswaldo } \\
\text { Hernández, David Díaz, Ariel Ruiz, Byron Ramírez, } \\
\text { Gerardo Gutiérrez, Néstor Morales. }\end{array}$ & $\begin{array}{l}\text { Vol. } 16 \\
\text { Núm. } 1 \\
(2016)\end{array}$ & $31 / 01 / 2017$ & 227 \\
\hline
\end{tabular}




\begin{tabular}{|c|c|c|c|c|}
\hline$\#$ & Título & Volumen & Fecha pub & $\begin{array}{c}\text { Descargas } \\
\text { PDF }\end{array}$ \\
\hline 5 & $\begin{array}{l}\text { Aprendizaje de la circunferencia aplicando el Modelo } \\
\text { de Van Hiele en estudiantes de undécimo grado de } \\
\text { Educación Secundaria de Río San Juan. Autores: Misael } \\
\text { Ariel Suárez Martínez, Joel Antonio Martínez Ortiz, } \\
\text { Eugenio Casimiro López Mairena. }\end{array}$ & $\begin{array}{l}\text { Vol. } 18 \\
\text { Núm. } 1 \\
(2017)\end{array}$ & 25/08/2017 & 219 \\
\hline 6 & $\begin{array}{l}\text { Identidad cultural de los jóvenes de Siuna, Costa Caribe } \\
\text { Norte de Nicaragua. Autores: Dayling Del Socorro Tórrez } \\
\text { Jarquín, Anielka Ellieth Urbina Larios, Lilia Del Rosario } \\
\text { Montoya Leal. }\end{array}$ & $\begin{array}{l}\text { Vol. } 18 \\
\text { Núm. } 1 \\
(2017)\end{array}$ & 25/08/2017 & 218 \\
\hline 7 & $\begin{array}{l}\text { Del otro lado de las cenizas. Autores: Eddy Alfonso } \\
\text { Salgado López. }\end{array}$ & $\begin{array}{l}\text { Vol. } 18 \\
\text { Núm. } 1 \\
(2017)\end{array}$ & $25 / 08 / 2017$ & 209 \\
\hline 8 & $\begin{array}{l}\text { Sistemas productivos de comunitarios mestizos en la } \\
\text { Costa Caribe Norte de Nicaragua. Autores: Jerónimo } \\
\text { Matamoros Raudez, Enrique Cordón Suárez. }\end{array}$ & $\begin{array}{l}\text { Vol. } 18 \\
\text { Núm. } 1 \\
(2017)\end{array}$ & $25 / 08 / 2017$ & 179 \\
\hline 9 & $\begin{array}{l}\text { Producción y calidad de forraje con enmiendas orgáni- } \\
\text { cas en pastura (Brachiaria brizantha), en la Costa Caribe } \\
\text { Sur de Nicaragua. Autores: Franklin Ariel López García, } \\
\text { Jarling Alberto Miranda, Wilson Antonio Calero Borge. }\end{array}$ & $\begin{array}{l}\text { Vol. } 18 \\
\text { Núm. } 1 \\
(2017)\end{array}$ & $25 / 08 / 2017$ & 144 \\
\hline 10 & $\begin{array}{l}\text { Educar para la vida: Un docente desde la pedagogía del } \\
\text { amor. Autores: Isidro Rodríguez Silva. }\end{array}$ & $\begin{array}{l}\text { Vol. } 17 \\
\text { Núm. } 2 \\
(2016)\end{array}$ & 03/02/2017 & 126 \\
\hline 11 & $\begin{array}{l}\text { Estrategias metodológicas para la enseñanza del uso y } \\
\text { manejo de las reglas ortográficas en el Instituto Rubén } \\
\text { Darío de Santa Rita, Costa Caribe Norte de Nicaragua. } \\
\text { Autores: Samara Sugey Sequeira Huetes, Erlinda Mejía } \\
\text { Martínez, Iván Jarquín Chavarría. }\end{array}$ & $\begin{array}{l}\text { Vol. } 18 \\
\text { Núm. } 1 \\
\text { (2017) }\end{array}$ & $25 / 08 / 2017$ & 122 \\
\hline 12 & $\begin{array}{l}\text { Vida, obra y pensamiento de MARCUS GARVEY. Autores: } \\
\text { Alta Hooker Blandford. }\end{array}$ & \begin{tabular}{|l|} 
Vol. 11 \\
Núm. 2 \\
$(2013)$ \\
\end{tabular} & $16 / 01 / 2014$ & 113 \\
\hline 13 & $\begin{array}{l}\text { Hábitat potencial del Danto (Tapires bairdi) en la Costa } \\
\text { Caribe Norte de Nicaragua. Autores: Jhon Albort Domeiz } \\
\text { Dambus, Harvey Hugh Smith Chow, Enrique Cordón } \\
\text { Suárez. }\end{array}$ & $\begin{array}{l}\text { Vol. } 18 \\
\text { Núm. } 1 \\
(2017)\end{array}$ & $25 / 08 / 2017$ & 102 \\
\hline 14 & $\begin{array}{l}\text { Perspectiva de los idiomas en la Costa Caribe de } \\
\text { Nicaragua. Autores: Ronald Amadeo Brooks Saldaña. }\end{array}$ & $\begin{array}{l}\text { Vol. } 8 \\
\text { Núm. } 2 \\
(2002)\end{array}$ & 26/01/2012 & 91 \\
\hline 15 & Poesía Costeña recopilación. Autores: Víctor Obando. & $\begin{array}{l}\text { Vol. } 8 \\
\text { Núm. } 2 \\
(2002)\end{array}$ & 26/01/2012 & 72 \\
\hline
\end{tabular}


EDUCACIÓN

\begin{tabular}{|c|c|c|c|c|}
\hline \# & Título & Volumen & Fecha pub & $\begin{array}{c}\text { Descargas } \\
\text { PDF }\end{array}$ \\
\hline 16 & $\begin{array}{l}\text { Actitudes hacia las matemáticas: un estudio en una es- } \\
\text { cuela rural de la Costa Caribe Sur de Nicaragua. Autores: } \\
\text { Eliel Jiménez Bonilla, William Oswaldo Flores López. }\end{array}$ & $\begin{array}{l}\text { Vol. } 18 \\
\text { Núm. } 1 \\
\text { (2017) }\end{array}$ & $25 / 08 / 2017$ & 55 \\
\hline 17 & Cultura afrocaribeña. Autores: Carmen Duran Jordain. & $\begin{array}{l}\text { Vol. } 2 \\
\text { Núm. } 1 \\
\text { (2000) }\end{array}$ & $26 / 03 / 2012$ & 55 \\
\hline 18 & $\begin{array}{l}\text { Acciones educativas para elevar el conocimiento de } \\
\text { la educación ambiental en la comunidad Natividad } \\
\text { del Municipio La Sierpe. Autores: Maité Felicia Valdivia } \\
\text { Valdés, Julio César Calderón Leiva. }\end{array}$ & $\begin{array}{l}\text { Vol. } 17 \\
\text { Núm. } 2 \\
\text { (2016) }\end{array}$ & 03/02/2017 & 51 \\
\hline 19 & $\begin{array}{l}\text { Cultura de poder. Literatura indígena y afrocaribeña en } \\
\text { Nicaragua. Autores: Carlos Alemán Ocampo. }\end{array}$ & $\begin{array}{l}\text { Vol. } 2 \\
\text { Núm. } 1 \\
(2000)\end{array}$ & $26 / 03 / 2012$ & 47 \\
\hline 20 & $\begin{array}{l}\text { Luchadores por la paz y el humanismo como paradigma: } \\
\text { Gandhi y Mandela. Autores: Ciril Omeir. }\end{array}$ & $\begin{array}{l}\text { Vol. } 12 \\
\text { Núm. } 1 \\
\text { (2014) }\end{array}$ & 17/02/2015 & 45 \\
\hline
\end{tabular}

\section{Ranking de universidades de Nicaragua, según Scimago Institutions Ranking, en base a documentos publicados en revistas académicas indizadas en Scopus, período 2012-2016.}

Según el ranking del Scimago Institutions Ranking para universidades de Nicaragua, la URACCAN ocupa el séptimo lugar, este ranking se hace en base al número total de documentos publicados en revistas académicas indizadas en Scopus, para el período 2012-2016 (cuadro 14).

Cuadro No. 14: Indicadores del Scimago Institutions Ranking para universidades de Nicaragua, según número total de documentos publicados en revistas académicas indizadas en Scopus, 2012-2016.

\begin{tabular}{|l|l|l|l|l|l|l|}
\hline No. & \multicolumn{1}{|c|}{ Organización } & $\begin{array}{c}\text { Cantidad de } \\
\text { Publicaciones }\end{array}$ & $\begin{array}{c}\text { Posición en } \\
\text { el país }\end{array}$ & $\begin{array}{c}\text { Posición en } \\
\text { Centroamérica }\end{array}$ & $\begin{array}{c}\text { Posición en } \\
\text { Latinoamérica }\end{array}$ & $\begin{array}{c}\text { Posición en } \\
\text { Iberoamérica }\end{array}$ \\
\hline 1 & UNAN-León & 129 & 1 & 9 & 383 & 472 \\
\hline 2 & $\begin{array}{l}\text { Universidad } \\
\text { Centroamericana }\end{array}$ & 32 & 2 & 21 & 472 & 561 \\
\hline 3 & UNAN-Managua & 31 & 3 & 22 & 473 & 562 \\
\hline 4 & $\begin{array}{l}\text { Universidad Nacional } \\
\text { de Ingeniería }\end{array}$ & 23 & 4 & 25 & 481 & 570 \\
\hline 5 & INCAE & 20 & 5 & 27 & 484 & 573 \\
\hline
\end{tabular}




\begin{tabular}{|l|l|l|l|l|l|l|}
\hline No. & \multicolumn{1}{|c|}{ Organización } & $\begin{array}{c}\text { Cantidad de } \\
\text { Publicaciones }\end{array}$ & $\begin{array}{c}\text { Posición en } \\
\text { el país }\end{array}$ & $\begin{array}{c}\text { Posición en } \\
\text { Centroamérica }\end{array}$ & $\begin{array}{c}\text { Posición en } \\
\text { Latinoamérica }\end{array}$ & $\begin{array}{l}\text { Posición en } \\
\text { Iberoamérica }\end{array}$ \\
\hline 6 & $\begin{array}{l}\text { Universidad Nacional } \\
\text { Agraria }\end{array}$ & 14 & 6 & 30 & 490 & 579 \\
\hline 7 & URACCAN & 5 & 7 & 38 & 499 & 588 \\
\hline 8 & $\begin{array}{l}\text { Universidad del Norte } \\
\text { de Nicaragua }\end{array}$ & 2 & 8 & 41 & 502 & 591 \\
\hline 9 & $\begin{array}{l}\text { Universidad } \\
\text { Politécnica de }\end{array}$ & 2 & 8 & 41 & 502 & 591 \\
\hline 10 & Bicaragua & 2 & 8 & 41 & 502 & 591 \\
\hline 11 & $\begin{array}{l}\text { Univ. Santo Tomas de } \\
\text { Oriente }\end{array}$ & 2 & 8 & 41 & 502 & 591 \\
\hline 12 & $\begin{array}{l}\text { Universidad } \\
\text { Americana }\end{array}$ & 1 & 9 & 42 & 503 & 592 \\
\hline 13 & $\begin{array}{l}\text { Univ. Católica Agrop. } \\
\text { del Trópico Seco }\end{array}$ & 1 & 9 & 42 & 503 & 592 \\
\hline
\end{tabular}

Fuente: Construcción propia a partir de datos de la presentación, "Investigación y estudios de posgrado en América Central: algunos indicadores y tendencias" (Alarcón Alba,2019).

\section{Reconocimientos nacionales}

Las dos revistas científicas de URACCAN, Ciencia e Interculturalidad y la Revista Universitaria del Caribe, han recibido reconocimientos honoríficos por parte del Consejo Nicaragüense de Ciencia y Tecnología de Nicaragua (CONICYT) "Por su esfuerzo en elevar la calidad y aplicación de los criterios del Sistema Regional de Información en Línea, para revistas científicas de América Latina, el Caribe, España y Portugal (LATINDEX) y lograr visibilidad de la producción científica de Nicaragua en Latin American Journal OnLine (LAMJOL)". En noviembre del 2013 lo recibe la revista Ciencia e Interculturalidad y en noviembre del 2016 lo recibe la Revista Universitaria del Caribe. 


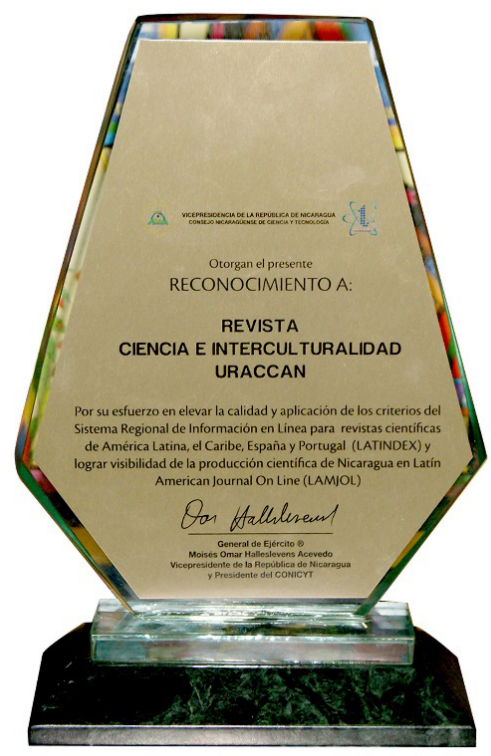

Figura No. 2: Reconocimiento, otorgado a la revista Ciencia e Interculturalidad, por parte del CONICYT.

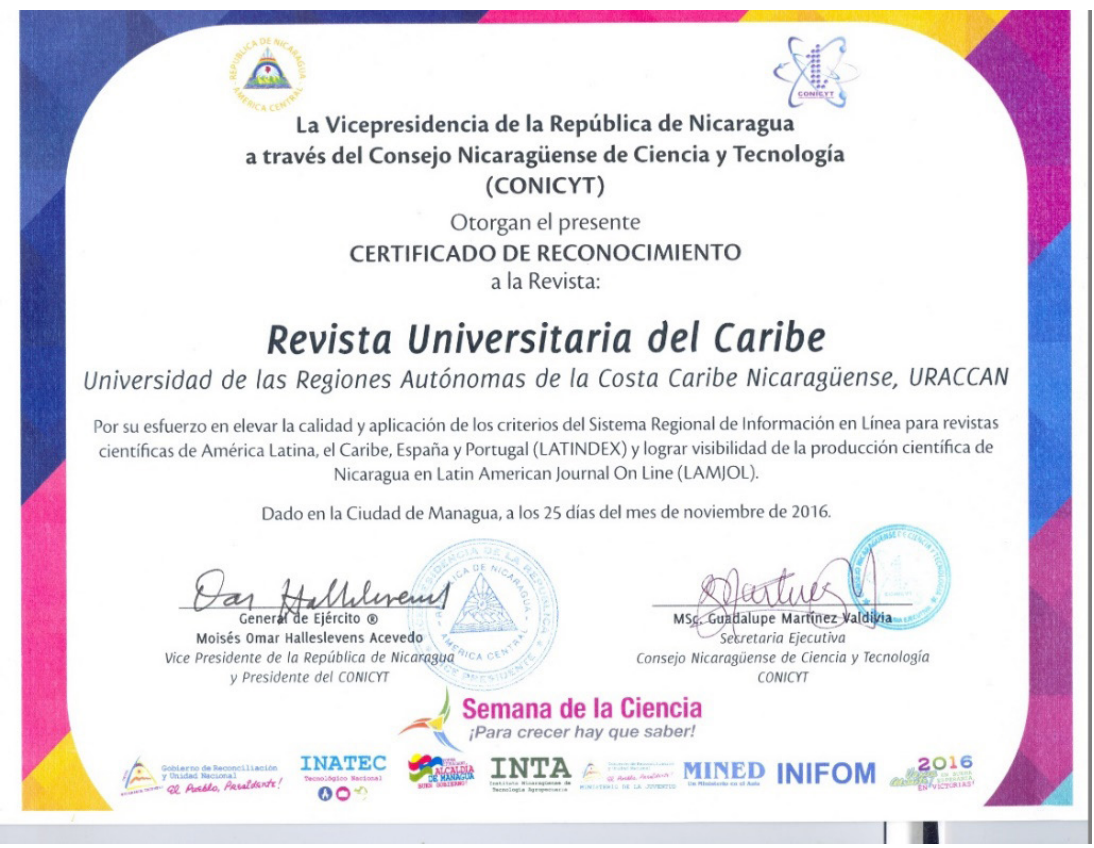

Figura No. 3: Certificado de reconocimiento, otorgado a la Revista Universitaria del Caribe, por parte del CONICYT. 


\section{Conclusiones}

La demanda de información científica actualizada por parte de los usuarios es creciente, y las revistas electrónicas representan la herramienta más eficiente en la distribución de los resultados de la investigación científica, con una significativa disminución de los costos de publicación.

La producción científica de URACCAN, en el período 2013-2017 osciló entre las 153 y 160 investigaciones concluidas por año, con un promedio de 157.4. Por recinto, los datos demuestran que la producción científica se distribuye en un $28.46 \%$ en el recinto Nueva Guinea, $26.30 \%$ en el recinto Las Minas, $23.76 \%$ en el recinto Bilwi y un $21.46 \%$ en el recinto Bluefields.

Del 2013 al 2017 la URACCAN publicó un total de 20 números de sus revistas científicas, Ciencia e Interculturalidad y la Revista Universitaria del Caribe, con 169 artículos, 89 en Ciencia e Interculturalidad y 80 en la Revista Universitaria del Caribe, en revistas internacionales se tienen registrados 5 artículos publicados; además se publicaron 21 libros y 11 documento referidos a políticas, normativas y reglamentos institucionales.

La publicación científica de la Universidad en formato digital ha sido muy exitosa, en el período de junio del 2011 a enero del 2018, en tres portales, se hicieron un total de 574,649 descargas de artículos en formato pdf, de estos, 333,488 descargas se hicieron en el Portal de revistas de URACCAN, 205,853 en Lamjol y 35,308 en el Portal de revistas de Nicaragua.

En el período de agosto del 2015 a noviembre del 2018, la revista Ciencia e Interculturalidad tiene el primer lugar en descargas de artículos de las revistas de universidades públicas, y el segundo lugar de 49 revistas alojadas en Lamjol.

En el ranking del Scimago Institutions Ranking para universidades de Nicaragua, la URACCAN ocupa el séptimo lugar, este ranking se hace en base al número total de documentos publicados en revistas académicas indizadas en Scopus, para el período 2012-2016.

Las dos revistas científicas de URACCAN, Ciencia e Interculturalidad y Revista Universitaria del Caribe, recibieron reconocimientos por parte del Consejo Nicaragüense de Ciencia y Tecnología de Nicaragua (CONICYT) "por su esfuerzo en elevar la calidad y aplicación de los criterios del Sistema Regional de Información en Línea, para revistas científicas de América Latina, el Caribe, España y Portugal (LATINDEX) y lograr visibilidad de la producción científica de Nicaragua en Latin American Journal OnLine (LAMJOL)". 
En materia de indizaciones, la revista Ciencia e Interculturalidad se encuentra en los siguientes sitios: i) Índices: ERIH PLUS (European Reference Index for the Humanities and Social Sciences); ii)Bases de datos: CATÁLOGO v1 LATINDEX (Sistema Regional de Información en línea para Revistas Científicas de América Latina, el Caribe, España y Portugal), CAMJOL (Central American Journals Online), CROSSREEF (Digital Object Identifier -DOI- Date Base), DIALNET (Fundación Dialnet), DOAJ (Directory of Open Access Journals) y REDIB (Red Iberoamericana de Innovación y Conocimiento Científico); iii) Directorios: CIRC (Clasificación Integrada de Revistas Científicas); iv) Portales: Portal de Revistas de Nicaragua (Consejo Nacional de Universidades de Nicaragua) y Portal de Revista de URACCAN (Universidad de las Regiones Autónomas de la Costa Caribe Nicaragüense).

En materia de indizaciones, la Revista Universitaria del Caribe se encuentra en los siguientes sitios: i) Bases de datos: CATÁLOGO v1 LATINDEX (Sistema Regional de Información en línea para Revistas Científicas de América Latina, el Caribe, España y Portugal), CAMJOL (Central American Journals Online) y CROSSREEF (Digital Object Identifier -DOI- Date Base); ii) Portales: Portal de Revistas de Nicaragua (Consejo Nacional de Universidades de Nicaragua), Portal de Revista de URACCAN (Universidad de las Regiones Autónomas de la Costa Caribe Nicaragüense); iii) Repositorios: Repositorio Universitario de Nicaragua (Consejo Nacional de Universidades), Repositorio Institucional de URACCAN (Universidad de las Regiones Autónomas de la Costa Caribe Nicaragüense) y Observatorio de la Autonomía (Universidad de las Regiones Autónomas de la Costa Caribe Nicaragüense).

\section{Agradecimiento}

Esta publicación obtuvo el financiamiento de: El Fondo de Asistencia Internacional de los Estudiantes y Académicos Noruegos, (SAIH).

\section{Lista de referencias}

Bush Carol y Williamson M. (2013). Diagnóstico situacional de la gestión investigativa en la Universidad de las Regiones Autónomas de la Costa Caribe Nicaragüense, Recinto Bilwi, para el período del 2010 - 2012. Proyecto de graduación. Bilwi.73. pág.

Consejo nacional de Universidades (2012). Plan Estratégico de la Educación Superior 2012-2021. CNU. Managua, Nicaragua.

Cortes, D. (2007). Medir la producción científica de los investigadores universitarios: la bibliometría y sus límites, p. 43-65. Revista de la Educación Superior, Vol. XXXIV (2), No. 142. 
Hernández, H. et al. (2005). Estrategia para la proyección del impacto. Revista Cubana de Educación Superior, No. 1. Trabajo presentado en la Junta Consultiva de Posgrado. Evento Internacional Universidad 2004, La Habana.

INASP. (2012). El Boletín Lamjol. Recuperado en: http://www.inasp.info/uploads/ filer_public/2013/04/og/lamjol_newsletter_1_spanish.pdf

INASP. (2014). El Boletín Lamjol. Recuperado en: https://www.uni.edu.ni/img/ Articulos/2015/01/22/Boletin-LAMJO-2014.pdf

Nave-Herrera, O.F. (2017). Metodologías e indicadores para medir el impacto de las investigaciones en instituciones de educación superior. Ponencia presentada en el Encuentro Nacional de Investigación, Posgrado y Extensión del CNU. Managua, Nicaragua.

Perera Lumbí, J. (2013). Ranking de artículos más leídos de la URACCAN publicados en sus revisas electrónicas con acceso abierto. Ciencia e Interculturalidad, 13(2), 21-46. https://doi.org/https://doi.org/10.5377/rci.v13i2.1275

Sioux Cumming. (2013). Estadísticas Ciencia e Interculturalidad en Latin American Journal Online (LAMJOL). Documento digital.

Spinak, E. (1998). Indicadores cienciométricos. Trabajo presentado en el Seminario sobre Evaluación de la Producción Científica, São Paulo.

URACCAN (2018). Informe final plan de mejora URACCAN 2015-2018. Managua, Nicaragua.

URACCAN (2014). Plan estratégico participativo de la URACCAN (PEI 2015-2019). Managua, Nicaragua.

URACCAN (2017). Indicadores para medir el impacto de la creación, recreación de conocimientos, saberes y prácticas en URACCAN. Managua, Nicaragua, 7 pág.

Zeledón O y Miranda F. (2010). Utilidad de las investigaciones monográficas de los graduados y graduadas de URACCAN, Nueva Guinea durante el período 2003-2009. (Tesis de maestría). 137 pág. 